\title{
Chemoattractive Mechanisms in Filamentous Fungi
}

\author{
Alexander Lichius ${ }^{1, *}$ and Kathryn M. Lord ${ }^{2}$ \\ ${ }^{1}$ Institute of Chemical Engineering, Vienna University of Technology, Austria \\ ${ }^{2}$ School of Biological Sciences, The University of Edinburgh, Scotland, United Kingdom
}

\begin{abstract}
Research on cell communication and differentiation in filamentous fungi has provided a number of novel insights into chemoattractive mechanisms in recent years. Still, identification of specific chemoattractant molecules, cognate receptors and downstream signaling pathways is strongly biased towards those involved in mating; probably due to the relative ease of functional genomic comparison to the budding yeast model. The multicellular nature of filamentous fungi, however, preserved a more complex morphology compared to unicellular fungi and revealed chemoattractive mechanisms lost during yeast evolution. Two hallmarks of this higher complexity are the formation of an interconnected colony network and the development of elaborate sexual reproductive organs. Morphogenesis of both structures depends on two different modes of chemoattraction: attraction to self and attraction to nonself. Nonself chemoattraction between genetically distinct mating partners is the basis for sexual reproduction and generally regulated through a bilateral sexpheromone/cognate-receptor system, widely but not exclusively equivalent to that known from yeasts. In contrast, selfchemoattraction between genetically identical cells is regulated independently of the sex-pheromone/cognate-receptor systems, and does not exist in yeast. Although both chemoattractive modes do share a number of molecular components, we are only beginning to understand how cell morphogenesis is regulated by means of gene expression and targeted protein recruitment during the establishment of self-fusion. This review provides an overview on the main morphogenetic elements involved in fungal chemoattraction, and summarizes our current understanding of the underlying molecular mechanisms of self- and nonself-fusion during filamentous fungal development.
\end{abstract}

Keywords: Cell fusion, chemotropism, mating systems, nonself recognition, self signaling.

\section{INTRODUCTION}

Chemoattraction describes the directional movement or growth of a cellular element along a chemoattractant gradient towards its source. Chemoattractive stimuli controlling fungal development include: sex pheromones; vegetative chemoattractants; nutrients such as carbohydrates, polysaccharides and amino acids; as well as molecules that elicit prey- or host-recognition by pathogenic and symbiotic species. Depending on the cellular element executing the directional response, two types of chemoattraction can be distinguished. We use the term chemotaxis (movement response) to describe the directed movement of, for example, a single cell, such as a flagellate spore, which has detached from the rest of the mycelium. Whereas, when a cellular protrusion of an otherwise immobile cell or mycelium, such as a germ tube or mature hypha, shows directed growth, we refer to it as chemotropism (growth or turning response). Negative chemotaxis and chemotropism, that is the movement or growth away from a chemorepellent source, are of equal importance for filamentous fungal development, but are not the subjects of this review.

*Address correspondence to this author at the Institute of Chemical Engineering/166-5, Vienna University of Technology, Gumpendorfer Strasse 1a, 1060 Vienna, Austria; Tel: +43(1)58801-166524;

Fax: +43(1)58801-17299; E-mail: alexander.lichius@tuwien.ac.at
Positive chemotaxis in fungi has been best documented in motile, flagellate zoospores of aquatic and soil fungi in the context of mating and nutrient substrate and host localization. Haploid gametes of the chytridiomycete Allomyces macrogynus, for instance, attract each other and fuse pairwise to produce diploid zygotes. Sirenin and parisin have been identified as the first diffusible male and female sex pheromones in fungi that induce spiral swimming patterns of gametes towards each other [1-3]. The cognate receptors of sirenin and parisin, however, have not yet been identified. Zoospores of anaerobic ruminal fungi utilize phenolic acids as chemoattractants to locate lignified tissue as a growth substrate within the gut of their host herbivores [4], whereas negatively geotactic zoospores of the phytopathogenic oomycete (a fungal-like organism, phylogenetically closer to brown algae and diatoms) Phytophthora sojae are specifically attracted by the isoflavones daidzein and genistein that are secreted from soy bean roots, to which cells attach, encyst and establish disease $[5,6]$. Recent studies implicated G-protein-coupled receptor (GPCR) and calcium signaling in the chemotactic response of P. sojae [7-9]. Other Phytophthora species, however, do not respond to these particular molecules, suggesting host specificity of these chemotactic responses. Zoospores of the marine saprophytic chytridiomycete Rhizophydium littoreum initially use positive phototaxis to reach the sea surface, then sense a broad range of polysaccharides and carbohydrates within the microenvironment of decaying plant or animal matter to locate the nutrient source [10]. Similar 
observations indicating only weak specificity, at best, towards certain nutritional cues were made with the pathogenic chytridiomycete Batrachochytrium dendrobatidis, which in recent years caused serious largescale declines in amphibian populations worldwide [11, 12], as well as with the facultative fish pathogen Saprolegnia parasitica [13]. Therefore, it is important to note that chemotaxis occurs generally, but not necessarily,in response to a specific molecule or class of molecule. An overview of the variety of specific and unspecific compounds used by fungal and oomycete plant- and animal-pathogens and -symbionts to locate suitable hosts has been summarized elsewhere [14]. Furthermore, in many cases chemotaxis will only function in combination with other stimuli. For the homing response of Phytophthora zoospores, for instance, these include at least three stimuli: chemotaxis, electrotaxis and induced encystment [15]; the latter describing the phenomenon that cyst aggregates of one species attract more zoospores of the same but not other Phytophthora species [16]. This is significant because it demonstrates that in addition to the response elicited towards the chemoattractant released by the host plant, Phytophthora cells also employ a second chemoattractant secretion and detection system for cell-cell communication and autoaggregation. Directional cell movement in oomycete and fungal zoospores therefore is a multimodal response with nonself chemotaxis, phototaxis, geotaxis and electrotaxis being one aspect, and species-specific cell-cell self-signaling being another facultative key component.

For sexual reproduction Phytophthora uses an entirely different signaling system involving collaborative pheromone production between opposite mating types (biosynthetic cross-talk; recently reviewed [17]). Mating type A2 cells use the plant hormone phytol as a putative precursor for the production of $\alpha 2$ pheromone, which upon perception induces the formation of sexual reproductive structures in its A1-type mating partner [18, 19]. A1 cells furthermore, convert $\alpha 2$ into $\alpha 1$ pheromone that, in turn, induces the formation of sexual reproductive structures in A2 cells [20]. Because each mating type can form both male and female reproductive structures [21, 22], and the threshold level diffusion range of the pheromones is usually limited, this system ensures the formation of opposite-mating-type oogonia and antheridia (female and male gametangia) in close proximity, facilitating subsequent nonself-fusion for the production of meiotic progeny. Information on the cognate $\alpha 1$ and $\alpha 2$ pheromone receptors involved in this interaction is not yet available, but would be most interesting, for example, for comparison to GPCRs involved in the infection-associated chemotaxis of $P$. sojae zoospores. More detailed structural and molecular information on the actual nonself-fusion process between Phytophthora oogonium and antheridium also seems to be lacking from the literature, and would be equally valuable for comparison to sexual fusion processes in the true fungi (see below).

The literature survey shows that in addition to the above, exemplified interactions of oomycete and fungal zoospores with their biotic and abiotic environment, research on molecular mechanisms of chemoattraction in filamentous fungi has still much to uncover in comparison to what has already been learned in bacteria, plants or animals. Therefore, it is an exciting ongoing challenge to identify more specific chemoattractant molecules and their cognate plasma membrane receptors used by filamentous fungi, and to understand which signaling pathways process these external signals to control cell morphogenesis.

Important filamentous model ascomycetes, such as Aspergillus, Fusarium, Magnaporthe, Neurospora, Podospora, Sordaria or Trichoderma species do not produce flagellate sexual or asexual spores capable of selfpropulsion, and thus rely on chemotropism alone to respond to external stimuli. Consequently, positive chemotropism in these species occurs during all developmental stages, including conidial germination and actively growing vegetative hyphae of the mature colony, as well as during morphogenesis of sexual reproductive structures. This generally involves hyphal elements that chemotropically interact either unilaterally (only one partner shows directed growth to the other) or bilaterally (both partners coordinate directed growth towards each other) in order to come into physical contact and establish cytoplasmic continuity by cell-cell fusion.

In the following sections we will compare morphogenesis and function of chemotropic structures during vegetative and sexual ascomycete development, and summarize our current understanding of the underlying molecular mechanisms that allow fungi to distinguish self from nonself, and coordinate self- and nonself-fusion, respectively. We will also briefly summarize positive chemotropism involved in the interaction of fungi with the abiotic environment, and with other fungi, plants or animals in the context of fungal foraging, symbiosis and pathogenesis.

\section{CHEMOATTRACTION DURING VEGETATIVE DEVELOPMENT}

Chemoattraction leading to cell fusion during the vegetative growth phase of filamentous fungi occurs most distinctively at two stages of development: (i) between conidial germlings at the onset of colony formation; and (ii) between mature hyphae (vegetative hyphal fusion; VHF) within certain areas of the functionally stratified colony. Most commonly, these fusion processes are investigated between isogenic (i.e. genetically identical) cellular elements, hence are defined as self-signaling and self-fusion events.

Vegetative nonself-fusion triggers programmed cell death. Vegetative nonself-fusion between genetically dissimilar individuals of the same species does occur. However, it leads to heterokaryon incompatibility (HI) responses if the fusion partners show allelic differences at so called heterokaryon (or vegetative) incompatibility (het) loci (reviewed in [23]). This nonself recognition mechanism triggers a localized programmed cell death (PCD) response around the fusion site that prevents spreading of genetically foreign nuclei throughout the receiving colony [24, 25]. Consequently, stable heterokaryons can only be formed by vegetative nonself-fusion when the interacting strains are compatible at all het loci. One well understood heterokaryon incompatibility system involves the het-c, pin-c and vib-1 loci of Neurospora crassa. In the event that a vegetative nonself-fusion leads to the formation of a hyphal compartment heterozygous for het-c and pin-c alleles, a 
nonself recognition signal is triggered by heterocomplex formation between HET-C and PIN-C at the plasma membrane [26]. This signal, in turn, is transduced by the putative transcription factor VIB-1, leading to growth inhibition, hyphal compartmentalization, PCD and the suppression of conidiation [27, 28]. Further details on the evolution, population genetics and selective mechanisms acting on the het-c and pin-c loci have been summarized elsewhere [29]. A recent study identified the kinase IME-2 of $N$. crassa as negative regulator of VIB-1-mediated PCD, acting through a parallel pathway [30]. Notably, mislocalization of the mitochondrial marker gene ARG-4 in the $\Delta$ ime-2 background implicated a novel role for mitochondria in nonself recognition and PCD.

Interestingly, HI responses following vegetative nonselffusion have recently been found to be suppressed in conidial germlings of Colletotrichum lindemuthianum, whereas nonself-fusion between mature hyphae of the same strains lead to rapid PCD [31]. Heterokaryotic mycelia that derived from nonself-fusion between $C$. lindemuthianum germlings survived for at least 30 hours with mixed phenotypic traits (differently colored nuclei), however, after which time they showed non-uniform distribution and color-associated clustering of nuclei in distinct sectors of the colony. This indicates that the heterokaryons were unstable, and the mycelium genetically purified itself by sorting the distinct nuclear populations in different sectors of the colony, and possibly separating these sectors through selective septal pore closure. The ability of $C$. lindemuthianum to transiently escape HI during germling fusion offers an opportunity for horizontal gene or chromosome transfer and non-meiotic recombination to promote non-sexual expansion of genetic diversity. Whether or not this phenomenon also occurs in other filamentous fungi awaits further experimental investigation. HI nonself recognition between mature vegetative hyphae generally occurs post-fusion. This implies that chemoattraction leading to nonself-fusion uses the same molecular machinery as used during self-signaling resulting in vegetative hyphal self-fusion between heterokaryon compatible partners, and does not include a nonself recognition step. Comparative studies investigating this in conidial germlings and mature hyphae in greater detail are to our knowledge not yet available, but urgently required.

Vegetative self-fusion employs dedicated cell protrusions and specialized signaling pathways. Neurospora crassa is currently the best-established model system to study morphogenetic and molecular details of selffusion between conidial germlings and vegetative hyphae in filamentous fungi. The first hyphal fusion mutant of $N$. crassa, Dham-1 (hyphal anastomosis mutant 1), was discovered in 1999 by Wilson and Dempsey [32], and the HAM-1 protein was later on found to be allelic with SOFT (SO), and further characterized [33-35]. Shortly after, HAM2 was identified and also characterized in more detail in the following years [36-38]. The precise molecular function of SOFT is still enigmatic, whereas HAM-2 has very recently been identified as a central part of the striatin-interacting protein phosphatase and kinase (STRIPAK) complex, critical for nuclear envelope localization of this complex [39].
Functional genomic comparison to nonself mating-cell fusion of the budding yeast Saccharomyces cerevisiae had a significant impact for these discoveries in $N$. crassa. The first components identified as essential for cell fusion in $N$. crassa by this approach were orthologues of the pheromoneresponse (PR) mitogen-activated protein kinase (MAPK) pathway, the MAP kinases NRC-1 and MAK-2, and the associated downstream transcription factor PP-1 [40-42]. The completion of the annotation of the $N$. crassa genome [43], and the availability of novel molecular tools allowing the rapid production of targeted gene deletion mutants [44, 45], were furthermore instrumental for the rapid progress in the field. Importantly, this approach revealed that the sex pheromone and cognate GPCR-based chemoattraction system of $N$. crassa, essential for sexual reproduction and orthologous to the nonself recognition system of mating budding yeast shmoos, was dispensable for vegetative selfsignaling and self-fusion of $N$. crassa [46-48]. Gene deletion mutants of sex pheromones or sex-pheromone receptors showed no defects during vegetative growth in a variety of other ascomycete fungi, including Sordaria macrospora, Podospora anserina and Aspergillus nidulans, confirming that the sex-pheromone chemoattraction system has an exclusive function for nonself recognition during sexual development in filamentous fungi and is generally not required for self-fusion [47, 49-51].

A milestone discovery for the investigation of selfsignaling and self-fusion in $N$. crassa was the existence of conidial anastomosis tubes (CATs). CATs are specialized cell protrusions that grow chemotropically towards each other, and are instrumental in establishing cell-cell contact prior to fusion between conidial germlings [37, 52]. In the mature mycelium, these functions are realized by fusion hyphae that develop prolifically as secondary branches of leading hyphae in the sub-periphery of the colony [38]. The vast majority of fusion-impaired mutants (hereafter referred to as "fusion mutant(s)") are equally affected at early and late developmental stages, indicating that the majority of molecular components involved in the regulation of germling and hyphal fusion, respectively, are shared. This suggests that the molecular mechanisms that control selffusion between conidial germlings are very similar, if not identical, to those controlling self-fusion between vegetative hyphae in the mature colony. The spatiotemporal recruitment dynamics of key proteins during both fusion processes, however, have been found to be significantly different. For example, for those proteins that constitute the polarized growth apparatus. Most strikingly, is the absence of a Spitzenkörper in conidial germlings, but its presence in mature hyphae. The Spitzenkörper (apical body) is a vesicle organization unit that has been shown to control directional tip growth in mature hyphae [53-56], and that was also suspected to be a key determinant for chemoattractant signaling between mature fusion hyphae and between conidial germlings $[57,58]$. We recently provided the first evidence that functional diversification of the small Rhotype GTPases $\mathrm{CDC}-42$ and $\mathrm{RAC}-1$ regulates opposite chemotropisms of CATs and germ tubes of $N$. crassa [59]. Time course analyses showed that repositioning of activated 
GTPase clusters within germ tube and CAT tip apices controls directional growth in the absence of a Spitzenkörper. These data suggest that a crescent-shaped vesicle supply center associated with the apical plasma membrane is sufficient to control directional tip growth in conidial germlings, whereas in mature hyphae the sub-apical vesicle supply center (i.e. Spitzenkörper) takes this role. The formation of a visible Spitzenkörper in germ tubes has already been suggested to mark the developmental transition point from germ tube to mature hyphae [53]. To what extent other molecular mechanisms of cell fusion are shared or are distinct between both developmental stages is subject of ongoing research.

Key insights into the mechanistic differences between germling and mature hyphal fusion were provided by the more recent discovery of a novel cell-cell communication system, which exclusively guides positive chemotropism of CATs, and involves the oscillatory recruitment of signaling molecules, including SO and MAK-2, to the tips of interacting CATs [34]. This system essentially allows genetically identical germlings to take the roles as signal sender and signal receiver in an alternating fashion, thereby recognizing each other as physiologically different, and facilitating self-fusion while avoiding auto-stimulation and auto-fusion during chemoattraction [60, 61]. Evidence for an equivalent oscillating self-recognition system for self-fusion between vegetative hyphae of the mature colony has so far not been found. As indicated above, the localization patterns of the known proteins involved in these oscillations in conidial germlings are different in mature hyphal tips in space and time, and do not involve oscillatory recruitment.

Vegetative self-fusion in a nutshell. Comprehensive reviews summarizing our current understanding about molecular details on the vegetative self-fusion machinery of $N$. crassa have recently been provided [60-65]. Key conclusions from the cumulative work on this topic include:

1. Molecular control over vegetative self-fusion involves numerous signaling components that are also used during sexual nonself-fusion of gametes, however, differs significantly in the upstream chemoattractive cell-cell recognition and communication mechanisms.

2. Vegetative self-fusion between conidial germlings is a bidirectional communication event, which requires two fusion-competent interaction partners. The first exception has very recently been discovered ( $\mathrm{ham}$ 11 ; [66]), but the fusion defect of a mutant can in most cases not be rescued through interaction with the wild type.

3. Chemoattraction leading to vegetative nonself-fusion between genetically dissimilar individuals appears to use the same molecular mechanism as used for vegetative self-fusion between isogenic individuals. Nonself recognition triggering HI responses occurs post-fusion.

4. The self-signaling chemoattractant molecule(s) and its putative receptor(s) are still unknown. Their discovery and the characterization of associated upstream selfsignaling components are amongst the most pressing research questions in the field.
5. Conidial germlings and mature hyphae appear to use different modes of the self-signaling mechanism to achieve cell-cell contact. Oscillatory protein recruitment for self-recognition and chemotropic growth has, so far, only been observed in conidial germlings. However, once physical contact is established, the general fusion machinery is switched on. Mechanistic differences during chemoattractant signaling at early and late developmental stages might be associated to the spatiotemporal re-organization of the polarized tip growth machinery that occurs during the transition from conidial germling to mature hypha.

6. So far, 67 proteins have been identified as important parts of the cell fusion machinery. Their functional roles are in: cell polarity regulation; MAP kinase, NADPH-dependent redox and $\mathrm{Ca}^{2+}$-mediated signal transduction; cell wall remodeling; vesicular trafficking and exo-/endocytosis; plasma membrane merger; and transcriptional regulation (for the complete list please refer to Table 1). Notable in this context is the recent study by Fu et al. 2011, who confirmed 11 previously known fusion mutants and identified 13 novel cell fusion proteins through a morphology-based screen of the complete gene deletion strain library of $N$. crassa [45, 67, 68]. Fig. (1) provides a schemativ overview on the germling fusion mechanism and indicates the known key functions of involved proteins.

The concept of "biological excitability" as a working model for the "ping-pong mechanism" of CAT chemotropism. To provide a theoretical model for informed experimental testing of the oscillatory cell-cell communication system of CAT chemotropism in $N$. crassa, for simplicity also termed the "ping-pong mechanism" [60], we have proposed the concept of biological excitability as possible mechanistic basis [69]. Key properties of an excitable system are: (i) the sudden onset of oscillation with a final amplitude due to an excitability threshold, and (ii) the absence of self-excitation due to a refractory period. Both features can be found in the cell fusion process of $N$. crassa germlings: cell A amplifies the received chemoattractant signal sent from cell $\mathrm{B}$, and then with a delay suppresses its response to return back to resting state. The excitation threshold guarantees that only super-threshold signals from cells that are near enough $(\leq 15 \mu \mathrm{m})$ to actually establish cell-cell contact (CATs can only extend to a maximum length of about $8 \mu \mathrm{m}$ ) lead to a response. The refractory period ensures that cell $\mathrm{A}$ is unable to respond to another stimulus, allowing time to elicit a response excitation pulse while preventing auto-excitation by that signal pulse. Cell B, in turn, receives the super-threshold response pulse from cell A. Hence, the two cells engaging in that process form an autonomous oscillator until fusion is established.

Molecularly the system requires an activator and an inhibitor. The activator is most likely the phosphorylated form of MAK-2, which amplifies itself rapidly upon perception of the inducing super-threshold signal, and also leads to the formation of the inhibitor that, in turn, slowly 
Table 1. Proteins involved in the regulation of self and nonself-fusion in N. crassa. The majority of "fusion mutants" that are known, to date, are fully defective in germling fusion and vegetative hyphal fusion, are female sterile but male fertile, and cannot be rescued through interaction with the wild type. Therefore, noteworthy (indicated in bold) are those proteins that when genetically deleted: (i) result in reduced fusion efficiency (where known, indicated as percentage of average wild-type germling fusion); (ii) allow fusion but with altered morphologies; (iii) are female and male sterile or (iv) are female and male fertile; (v) do form CATs but are unable to initiate or engage into chemotropic self-signaling (CAT homing); (vi) show increased fusion compared to the wild type, or (vii) can be rescued through interaction with a fusion competent partner, such as the wild type.

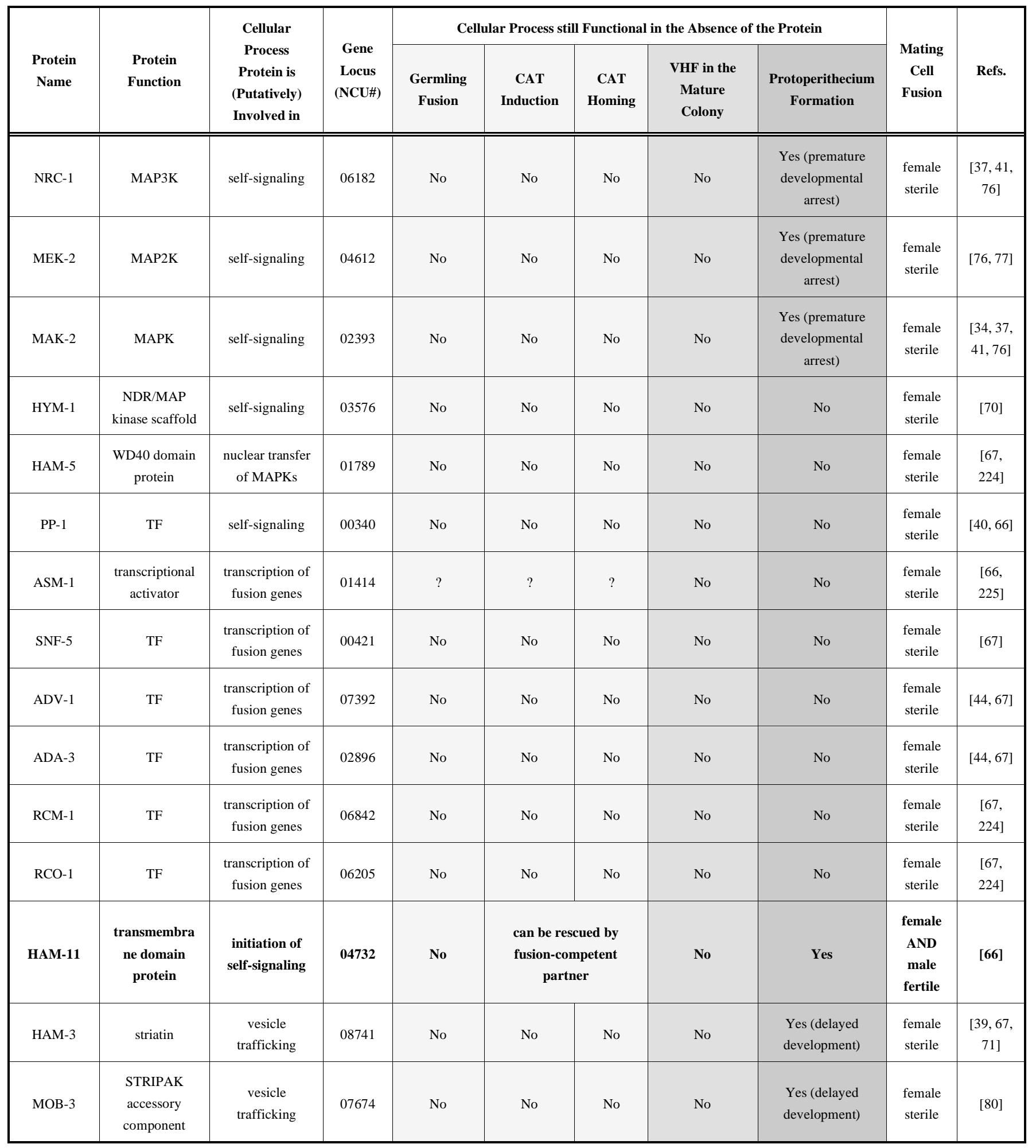


Table 1. contd...

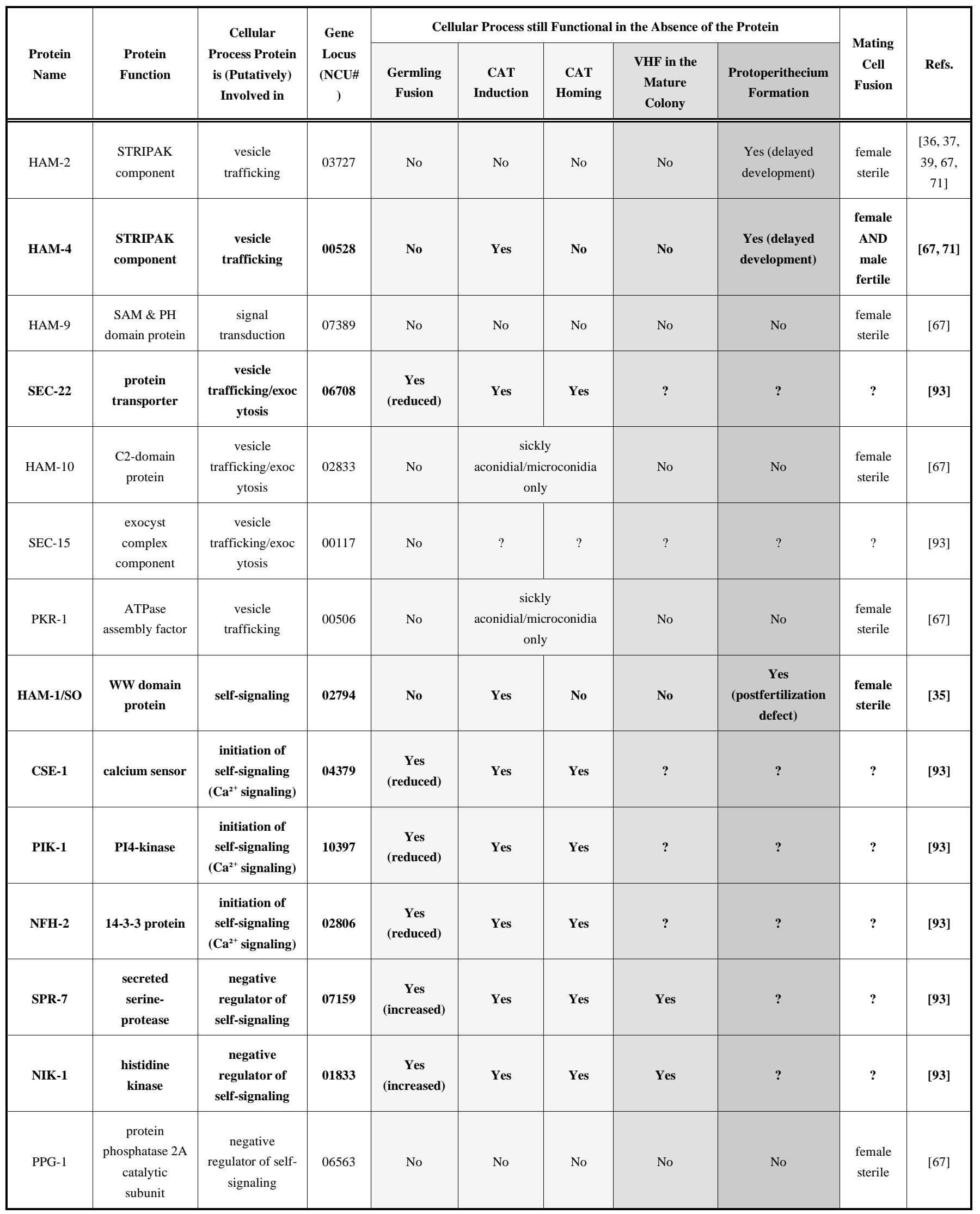


Table 1. contd...

\begin{tabular}{|c|c|c|c|c|c|c|c|c|c|c|}
\hline \multirow[b]{2}{*}{$\begin{array}{l}\text { Protein } \\
\text { Name }\end{array}$} & \multirow[b]{2}{*}{$\begin{array}{c}\text { Protein } \\
\text { Function }\end{array}$} & \multirow{2}{*}{$\begin{array}{c}\text { Cellular } \\
\text { Process } \\
\text { Protein is } \\
\text { (Putatively) } \\
\text { Involved in }\end{array}$} & \multirow{2}{*}{$\begin{array}{l}\text { Gene } \\
\text { Locus } \\
\text { (NCU\#) }\end{array}$} & \multicolumn{5}{|c|}{ Cellular Process still Functional in the Absence of the Protein } & \multirow{2}{*}{$\begin{array}{c}\text { Mating } \\
\text { Cell } \\
\text { Fusion }\end{array}$} & \multirow[b]{2}{*}{ Refs. } \\
\hline & & & & $\begin{array}{l}\text { Germling } \\
\text { Fusion }\end{array}$ & $\begin{array}{c}\text { CAT } \\
\text { Induction }\end{array}$ & $\begin{array}{c}\text { CAT } \\
\text { Homing }\end{array}$ & $\begin{array}{l}\text { VHF in the } \\
\text { Mature } \\
\text { Colony }\end{array}$ & $\begin{array}{c}\text { Protoperithecium } \\
\text { Formation }\end{array}$ & & \\
\hline CDC-42 & GTPase & cell polarity & 06067 & No & No & No & No & ? & $\begin{array}{c}\text { female } \\
\text { sterile }\end{array}$ & $\begin{array}{l}{[59,} \\
226]\end{array}$ \\
\hline RAC-1 & GTPase & cell polarity & 02160 & No & No & No & No & No & $\begin{array}{c}\text { female } \\
\text { sterile }\end{array}$ & $\begin{array}{c}{[59,67,} \\
226]\end{array}$ \\
\hline CDC-24 & GEF & cell polarity & 06454 & No & No & No & No & $?$ & ? & [226] \\
\hline SPA-2 & $\begin{array}{l}\text { polarisome } \\
\text { scaffold }\end{array}$ & cell polarity & 03115 & $\begin{array}{c}\text { Yes } \\
\text { (reduced) }\end{array}$ & Yes & Yes & Yes & $?$ & $?$ & $\begin{array}{l}{[79,} \\
227]\end{array}$ \\
\hline BNI-1 & formin & cell polarity & 01431 & \multicolumn{3}{|c|}{ aconidiate } & $\begin{array}{c}\text { Yes } \\
\text { (derepressed } \\
\text { at colony } \\
\text { periphery) }\end{array}$ & ? & ? & $\begin{array}{l}{[79,} \\
228]\end{array}$ \\
\hline BUD-6 & $\begin{array}{l}\text { actin- } \\
\text { interaction } \\
\text { protein }\end{array}$ & cell polarity & 08468 & \multicolumn{3}{|c|}{ aconidiate } & $\begin{array}{c}\text { Yes } \\
\text { (derepressed } \\
\text { at colony } \\
\text { periphery) }\end{array}$ & $?$ & ? & [79] \\
\hline COT-1 & NDR kinase & cell polarity & 07296 & Yes & Yes & Yes & Yes & Yes & Yes & $\begin{array}{c}{[70,77,} \\
80]\end{array}$ \\
\hline MOB-2A/B & MOB proteins & cell polarity & $\begin{array}{l}03314 / \\
07460\end{array}$ & Yes & Yes & Yes & Yes & Yes & Yes & $\begin{array}{c}{[70,77,} \\
80]\end{array}$ \\
\hline POD-6 & GC kinase & cell polarity & 11235 & Yes & Yes & Yes & Yes & Yes & Yes & $\begin{array}{l}{[70,77,} \\
80, \\
229]\end{array}$ \\
\hline MSS-4 & PI4P 5-kinase & cell polarity & 02295 & \multicolumn{3}{|c|}{$\begin{array}{c}\text { essential protein for polarized tip growth; } \\
\text { role in cell fusion is deduced from its } \\
\text { localization to homing and fusing CAT } \\
\text { tips }\end{array}$} & ? & ? & ? & [78] \\
\hline AMPH-1 & amphiphysin & $\begin{array}{l}\text { vesicle } \\
\text { trafficking/endo } \\
\text { cytosis }\end{array}$ & 01069 & No & \multicolumn{2}{|c|}{ almost aconidiate } & No & No & $\begin{array}{c}\text { female } \\
\text { sterile }\end{array}$ & [67] \\
\hline GYP-5 & GAP & $\begin{array}{c}\text { vesicle } \\
\text { trafficking/end } \\
\text { ocytosis }\end{array}$ & 06362 & $\begin{array}{c}\text { Yes } \\
\text { (increased) }\end{array}$ & Yes & Yes & Yes & ? & ? & [93] \\
\hline BEM-1 & $\begin{array}{c}\text { MAPK/GTPas } \\
\text { e scaffold }\end{array}$ & $\begin{array}{c}\text { self- } \\
\text { signaling/cell } \\
\text { polarity }\end{array}$ & 06593 & Yes $(20 \%)$ & Yes & Yes & No & Yes & $\begin{array}{l}\text { female } \\
\text { AND } \\
\text { male } \\
\text { fertile }\end{array}$ & [72] \\
\hline CLA-4 & PAK & cell polarity & 00406 & $\begin{array}{c}\text { Yes } \\
\text { (reduced) }\end{array}$ & No & No & $\begin{array}{c}\text { Yes (lateral } \\
\text { fusion) }\end{array}$ & ? & ? & [59] \\
\hline RO-6 & $\begin{array}{l}\text { dynein } \\
\text { intermediate } \\
\text { chain } 2\end{array}$ & $\begin{array}{l}\text { cytoskeleton } \\
\text { remodeling }\end{array}$ & 09142 & No & Yes & No & No & No & $\begin{array}{c}\text { female } \\
\text { sterile }\end{array}$ & [67] \\
\hline
\end{tabular}


Table 1. contd...

\begin{tabular}{|c|c|c|c|c|c|c|c|c|c|c|}
\hline \multirow[b]{2}{*}{$\begin{array}{l}\text { Protein } \\
\text { Name }\end{array}$} & \multirow[b]{2}{*}{$\begin{array}{l}\text { Protein } \\
\text { Function }\end{array}$} & \multirow{2}{*}{$\begin{array}{c}\text { Cellular } \\
\text { Process Protein } \\
\text { is (Putatively) } \\
\text { Involved in }\end{array}$} & \multirow{2}{*}{$\begin{array}{c}\text { Gene } \\
\text { Locus } \\
\text { (NCU\# } \\
\text { ) }\end{array}$} & \multicolumn{5}{|c|}{ Cellular Process still Functional in the Absence of the Protein } & \multirow[b]{2}{*}{$\begin{array}{c}\text { Mating } \\
\text { Cell } \\
\text { Fusion }\end{array}$} & \multirow[b]{2}{*}{ Refs. } \\
\hline & & & & $\begin{array}{c}\text { Germling } \\
\text { Fusion }\end{array}$ & $\begin{array}{c}\text { CAT } \\
\text { Induction }\end{array}$ & $\begin{array}{c}\text { CAT } \\
\text { Homing }\end{array}$ & $\begin{array}{l}\text { VHF in the } \\
\text { Mature } \\
\text { Colony }\end{array}$ & $\begin{array}{c}\text { Protoperithecium } \\
\text { Formation }\end{array}$ & & \\
\hline RO-11 & $\begin{array}{c}\text { dynein/dynacti } \\
\text { n subunit }\end{array}$ & $\begin{array}{l}\text { cytoskeleton } \\
\text { remodeling/nucl } \\
\text { ear distribution }\end{array}$ & 08566 & No & Yes & No & No & No & $\begin{array}{l}\text { female } \\
\text { sterile }\end{array}$ & {$[67,83]$} \\
\hline ATG-8 & $\begin{array}{l}\text { subunit of MT- } \\
\text { associated } \\
\text { protein }\end{array}$ & $\begin{array}{l}\text { cytoskeleton } \\
\text { remodeling }\end{array}$ & 01545 & No & Yes & No & No & No & $\begin{array}{l}\text { female } \\
\text { sterile }\end{array}$ & [67] \\
\hline ARP-2 & $\begin{array}{c}\text { ARP-2/3 } \\
\text { complex } \\
\text { subunit }\end{array}$ & $\begin{array}{l}\text { cytoskeleton } \\
\text { remodeling }\end{array}$ & 07171 & Yes $(20 \%)$ & Yes & Yes & $?$ & $?$ & $?$ & {$[83]$} \\
\hline ARPC3 & $\begin{array}{c}\text { ARP-2/3 } \\
\text { complex 21 } \\
\text { kDa subunit }\end{array}$ & $\begin{array}{l}\text { cytoskeleton } \\
\text { remodeling }\end{array}$ & 09572 & Yes $(30 \%)$ & Yes & Yes & $?$ & $?$ & $?$ & [83] \\
\hline$?$ & $\begin{array}{c}\text { ARP-2/3 } \\
\text { complex } 20 \\
\text { kDa subunit }\end{array}$ & $\begin{array}{l}\text { cytoskeleton } \\
\text { remodeling }\end{array}$ & 01918 & Yes $(10 \%)$ & Yes & Yes & $?$ & $?$ & $?$ & [83] \\
\hline NOX-1 & $\begin{array}{l}\text { NADPH } \\
\text { oxidase }\end{array}$ & redox signaling & 02110 & No & Yes $(20 \%)$ & No & No & $\begin{array}{c}\text { Yes (premature } \\
\text { developmental } \\
\text { arrest) }\end{array}$ & $\begin{array}{c}\text { female } \\
\text { sterile }\end{array}$ & $\begin{array}{c}{[67,73,} \\
90]\end{array}$ \\
\hline NOR-1 & $\begin{array}{l}\text { NOX } \\
\text { regulator }\end{array}$ & redox signaling & 07850 & No & Yes $(20 \%)$ & No & No & $\begin{array}{c}\text { Yes (premature } \\
\text { developmental } \\
\text { arrest) }\end{array}$ & $\begin{array}{c}\text { female } \\
\text { sterile }\end{array}$ & $\begin{array}{c}{[67,73,} \\
90]\end{array}$ \\
\hline ARG-15 & $\begin{array}{c}\text { acetylornithin } \\
\text { e-glutamate } \\
\text { transacetylase }\end{array}$ & $\begin{array}{c}\text { NOX } \\
\text { signaling/redox } \\
\text { detoxification }\end{array}$ & 05622 & $\begin{array}{c}\text { Yes } \\
\text { (reduced) }\end{array}$ & Yes & Yes & $?$ & $?$ & $?$ & [93] \\
\hline HAM-7 & $\begin{array}{l}\text { GPI-anchored } \\
\text { protein }\end{array}$ & $\begin{array}{l}\text { initiation of self- } \\
\text { signaling }\end{array}$ & 00881 & No & No & No & No & No & $\begin{array}{l}\text { female } \\
\text { sterile }\end{array}$ & $\begin{array}{c}{[66,67,} \\
74]\end{array}$ \\
\hline MIK-1 & MAP3K & $\begin{array}{c}\text { initiation of } \\
\text { self- } \\
\text { signaling/cell } \\
\text { wall remodeling }\end{array}$ & 02234 & No & Yes $(20 \%)$ & No & No & $\begin{array}{c}\text { Yes (premature } \\
\text { autolysis) }\end{array}$ & $\begin{array}{c}\text { female } \\
\text { sterile }\end{array}$ & $\begin{array}{c}{[73,76,} \\
77]\end{array}$ \\
\hline MEK-1 & MAP2K & $\begin{array}{c}\text { initiation of } \\
\text { self- } \\
\text { signaling/cell } \\
\text { wall remodeling }\end{array}$ & 06419 & No & Yes $(20 \%)$ & No & No & $\begin{array}{c}\text { Yes (premature } \\
\text { autolysis) }\end{array}$ & $\begin{array}{r}\text { female } \\
\text { sterile }\end{array}$ & $\begin{array}{r}{[70,73,} \\
76,77]\end{array}$ \\
\hline MAK-1 & MAPK & $\begin{array}{c}\text { initiation of } \\
\text { self- } \\
\text { signaling/cell } \\
\text { wall remodeling }\end{array}$ & 11376 & No & Yes $(20 \%)$ & No & No & $\begin{array}{c}\text { Yes (premature } \\
\text { autolysis) }\end{array}$ & $\begin{array}{c}\text { female } \\
\text { sterile }\end{array}$ & $\begin{array}{c}{[73,76,} \\
77]\end{array}$ \\
\hline GPIG-1 & GPI-anchor & $\begin{array}{l}\text { cell wall } \\
\text { remodeling }\end{array}$ & 09757 & & ly aconidiate & & No & No & $\begin{array}{c}\text { female } \\
\text { sterile }\end{array}$ & [230] \\
\hline GPIP-1 & GPI-anchor & $\begin{array}{l}\text { cell wall } \\
\text { remodeling }\end{array}$ & 06663 & & ly aconidiate & & No & No & $\begin{array}{c}\text { female } \\
\text { sterile }\end{array}$ & {$[230]$} \\
\hline
\end{tabular}


Table 1. contd...

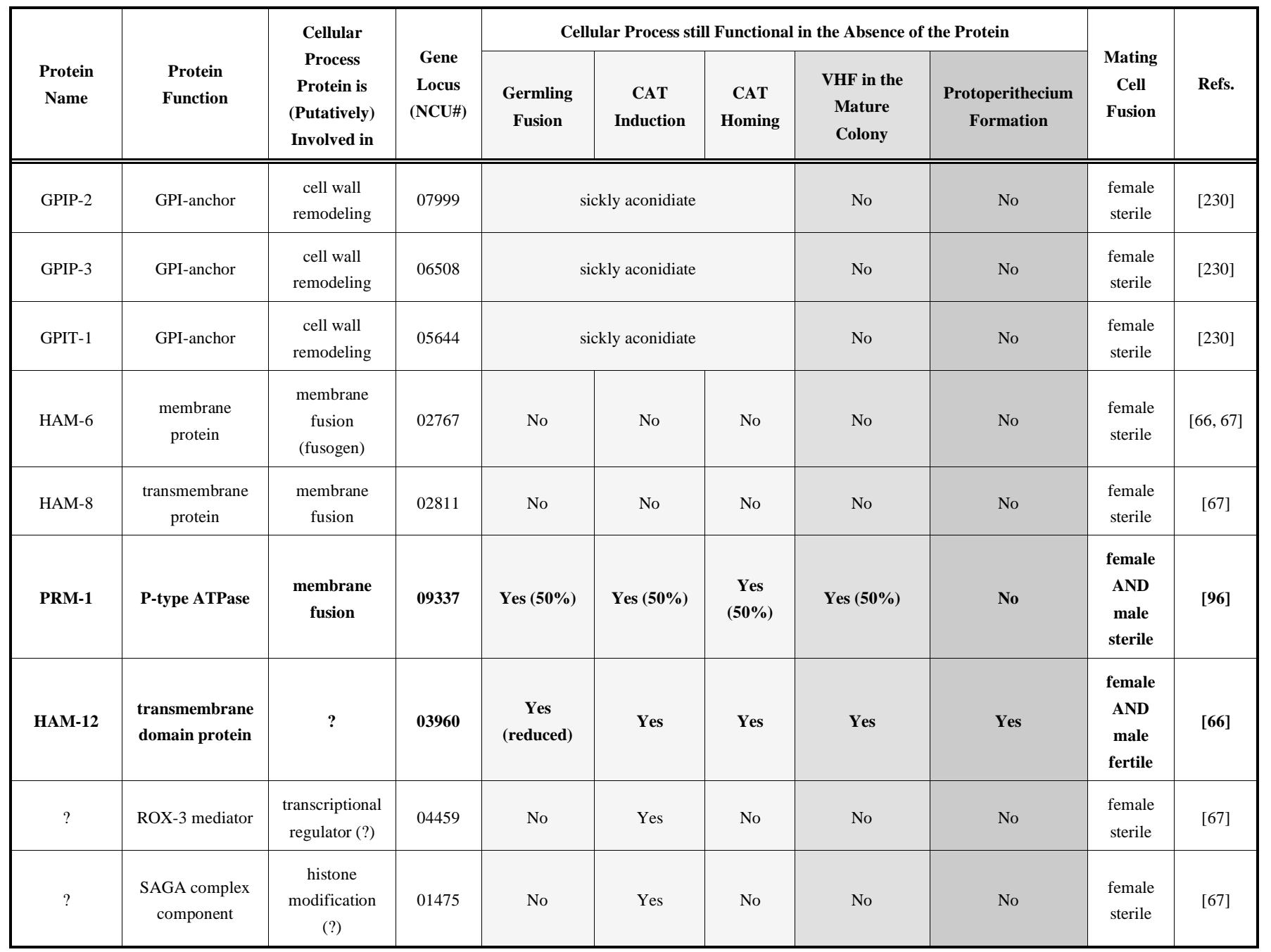

(?) Question marks indicate unknown protein functions

suppresses the activator. MAK-2 might also be the inhibitor, in case inhibition is simply achieved by depletion of the activator, e.g. through dephosphorylation of MAK-2. SO seems to be involved in coordinating pooling and fusion of vesicles containing the chemoattractant with the plasma membrane. Rapid release of a large number of chemoattractant vesicles is believed to generate the required super-threshold signal pulse, which needs to occur during MAK-2's refractory period, and is the reason why SO and MAK-2 oscillate out-of-phase with each other.

Three key pathways need to be integrated for successful cell-cell fusion: self-signaling, directional tip growth and cell wall remodeling. Recent investigations have greatly contributed to the identification of additional components of the oscillatoryself-signaling network and how it is integrated with directional polarized CAT tip growth and cell wall remodeling.

MAK-2 is the terminal MAP kinase in the three-tiered PR MAPK cascade of $N$. crassa. Its upstream companions, MEK-2 (MAP2K) and NRC-1 (MAP3K), were also found to oscillate together with MAK-2, strongly suggesting that the complete PR MAPK cascade is part of the self-signaling mechanism controlling CAT homing [70]. Notably, MAK-2 also accumulates around the opening fusion pore, suggesting functions during post-contact stages of fusion [34]. The proof that the Ste12-like transcription factor PP-1 indeed regulates signaling events downstream of MAK-2 was only recently provided [66]. Not surprisingly, PP-1 was found constantly localized to the nucleus, indicating that oscillatory recruitment of signaling proteins during CAT chemotropism might be spatially restricted to the cell cortex. Using an RNAseq approach the authors showed that the expression of 16 of the 40 known fusion proteins was dependent on PP-1 function. This important study furthermore identified a number of novel fusion proteins, most notably HAM-11. Sham-11 is a so far unique fusion mutant because it only fails to initiate chemotropic interactions, but it can be engaged by a fusion competent partner [66]. This suggests a role for HAM-11 in switching on oscillatory signaling upon the perception of the first super-threshold pulse released by a near-enough CAT. $\Delta$ ham-11 is also the third fusion mutant (after $\Delta$ ham-4 [71] and $\Delta b e m-1$ [72]) with full male AND female fertility, and displays some interesting phenotypic features that make it distinct from "ordinary" cell fusion mutants [66]. 
Of the two other MAPK cascades found in $N$. crassa, regulating cell wall integrity (CWI) and osmoregulation (OS), only the CWI MAPK is involved in cell fusion although it seems to have only a supporting role during chemotropism. MAK-1, the terminal MAP kinase of the CWI MAPK cascade, is only weakly recruited to CAT tips during homing and does not oscillate, but becomes strongly recruited to the fusion site upon contact and disappears once fusion pore formation is complete [73]. The intracellular dynamics of MAK-1's upstream companions, MIK-1 (CWI MAP3K) and MEK-1 (CWI MAP2K), have not yet been published, but preliminary data indicate that both follow those of MAK-1. Conidial germlings of CWI MAPK mutants produce CATs at low frequency (about $20 \%$ of the CAT formation rate of the wild type), but do not engage in chemotropic self-signaling [73]. This suggests that the CWI MAPK cascade is involved in early stages of establishing communication, whereas the strong accumulation of these MAPKs, upon contact at the incipient fusion site, points to a more prominent role in cell wall remodeling during cell-cell attachment and fusion pore formation.

Recent studies provided some evidence that activation of MAK-1 might also occur in a contact-dependent manner [74, 75]. WSC- 1 and WSC- 2 of $N$. crassa were identified as plasma membrane sensors that transduce signals into the CWI MAPK cascade in the context of cell wall repair [74]. Furthermore, the GPI-anchored membrane protein HAM-7 was found to be essential for cell fusion and, in addition to WSC-1, is essential for the activation of MAK-1. Interestingly, HAM-7 was not required for phosphorylation of MAK-2 during cell fusion, which suggests that a putative contact-related signal is processed through the CWI MAPK cascade without crosstalk to the PR MAPK. WSC-1dependent activation of MAK-1 is mediated through GTPase RHO-1, activated by its specific GTPase exchange factor (GEF) RGF-1 which also physically interacts with WSC-1, and protein kinase $\mathrm{C}(\mathrm{PKC})$ [75].

Notably, core components of the OS MAPK cascade, comprising OS-4 (MAP3K), OS-5 (MAP2K) and OS-2 (MAPK), are completely dispensable for cell fusion [76]. Earlier studies reporting $\Delta o s-4, \Delta o s-5$ and $\Delta o s-2$ as fusion mutants, unfortunately suffered from false fusion defects in the corresponding $\mathrm{KO}$ strains available from the FGSC collection at the time. It has become clear that unwanted mutations, in addition to the targeted gene deletion, can introduce a so called "soft-like" phenotype, characterized by a "flat conidiation" pattern, and defects in protoperithecium morphogenesis and cell fusion. Hence, rigorous genotyping and cosegregation analyses of each mutant strain are required to verify that only the intended gene deletion is responsible for the observed cell fusion defect $[67,74,76]$.

In conclusion, only two of the three MAPK signaling cascades are involved in the regulation of cell fusion in $N$. crassa, and both appear to have distinct but also overlapping functions. The PR MAPK cascade seems to have the leading role in oscillatory self-signaling during the pre-contact phase of cell fusion. In contrast, the CWI MAPK cascade assists in the initiation of cell communication, but has its main function during post-contact processes, including cell wall remodeling for cell-cell attachment and fusion pore opening.
Cross-talk between signaling pathways coordinates oscillatory self-signaling with directional CAT tip growth. Several recent studies identified a number of accessory proteins that through their dual-use properties in parallel signaling pathways can integrate different cellular processes. For example, Dettman et al.[70] identified HYM1 as a scaffolding protein for the assembly of the NDR kinase COT-1/MOB-2/POD-6 complex controlling polarized cell protrusion through COT-1 activation. In parallel, HYM1 acts as scaffold for the PR MAP kinase components NRC1 and MEK-2, regulating self-signaling. In its latter function, HYM-1 has been suggested as regulating on-off switching of MAK-2 by controlling shuttling of the kinase between nucleus, cytoplasm and plasma membrane [70]. Neither HYM-1 nor COT-1, however, have been observed to oscillate, most likely representing their general function during establishment and maintenance of polarized tip growth. Interestingly, mutations in cot- 1 have been found to suppress the vegetative hyphal fusion defect of $\Delta m a k-2$ [77].

Another key regulatory protein in this context is the phosphoinositide kinase MSS-4 [78]. Due to its essential nature, the effect of loss-of-function of MSS-4 on cell fusion could not be investigated. Live cell imaging analysis, however, showed that MSS-4 stably localized as apical cap to CAT tips and concentrated at cell fusion sites, suggesting that formation of $\mathrm{PtIns}(4,5) \mathrm{P} 2$ in the apical tip plasma membrane contributes to the establishment of lipid microdomains. These microdomains might serve as localized recruitment platforms for the polarized growth machinery, and probably contribute to membrane rearrangements required for the establishment of cytosolic continuity between fusing cells.

The three core polarisome components of $N$. crassa, SPA-2, BUD-6 and BNI-1 also showed apical cap localization during CAT tip growth, accumulation at the fusion site and disassembly when polarized growth was terminated upon completion of the fusion pore [79]. Interestingly, genetic deletion of either polarisome component did not cause severe cell fusion defects. In contrast to $\Delta s p a-2$ that showed only delayed and reduced germling and mature hyphal fusion, $\Delta b u d-6$ and $\Delta b n i$ 1 displayed an unexpected hyphal tip fusion phenotype at the colony periphery [79]. The severe deregulation of polarized tip growth and lack of hyphal differentiation in the two latter mutants probably abrogated the usual blockage of hyphal fusion at the colony periphery. The absence of conidia in $\Delta b u d-6$ and $\Delta b n i-1$, unfortunately, did not allow cytological analysis of germling fusion in these strains.

Another protein that bridges the functions of the polarity machinery and the ping-pong self-signaling system is BEM1 [72]. BEM-1 has been proposed to act in different signaling complexes, that may or may not require interaction with its PB1 domain. Components of the cell polarity machinery require this interaction and are needed for CAT formation. Genetic deletion of bem-1 resulted in delayed and reduced fusion. Established fusion connections were morphologically altered and did not show signs of directional, chemotropic growth. The PB1 domain was found to be dispensable for signal transduction leading to recruitment and activation of MAK-2 at CAT tips. BEM-1, 


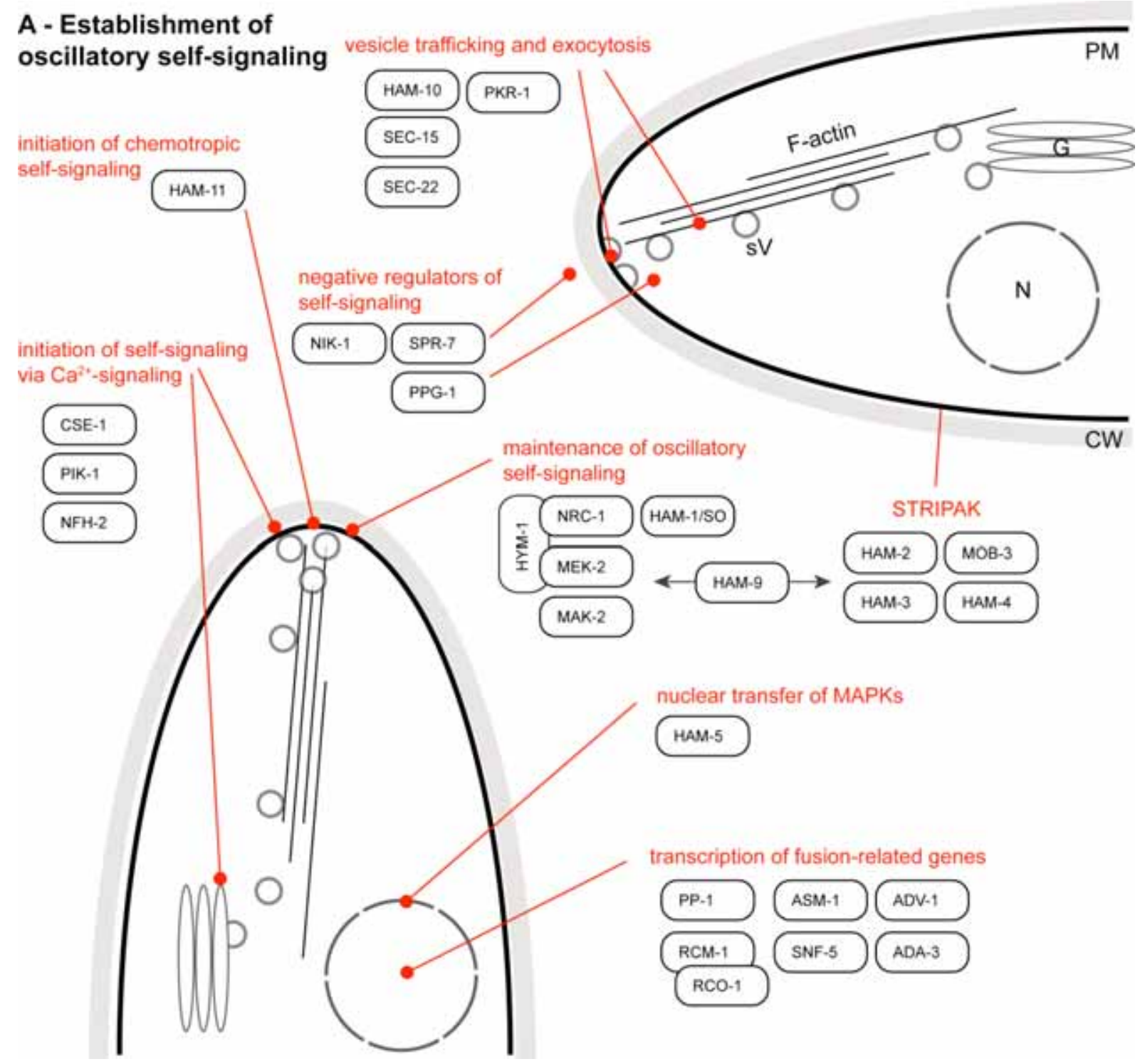

Fig. (1A). Establishment of oscillatory self-signaling. Germlings of $N$. crassa are believed to constitutively release low levels of an unknown, diffusible chemoattractant molecule that is recognized by a yet unknown cognate receptor in the plasma membrane of interaction partners, as soon as cells become sufficiently close $(\leq 15 \mu \mathrm{m})$ to each other. Chemoattractant receptor activation, in turn, activates the PR MAPK cascade (NRC-1/MEK-2/MAK-2), which feeds into various signaling pathways required to engage in cell-cell fusion. HYM-1 has recently been identified as one of the upstream components capable of interacting with NRC-1 and MEK-2. The WD40 domain protein HAM-5 has been implicated to mediate nuclear transfer of MAP kinases, such as MAK-2. Nuclear MAK-2 activates the transcription factor PP-1 that triggers the expression of fusion-related genes. ASM-1, SNF-5, ADV-1, ADA-3 and the functional heterodimer RCM-1/RCO-1, are additional transcriptional regulators required for self-fusion. Their target genes, however, await identification. PP-1 controls the transcription of HAM-11, which is believed to initiate oscillatory self-signaling by kick-starting a positive feedback loop upon initial MAK-2 activation. This includes increased recruitment of the PR MAPK cascade components into plasma membrane-associated signaling clusters, and phosphorylation of MAK-2. STRIPAK complex components, including HAM-3, MOB-3, HAM-2, and HAM-4, likely co-regulate the assembly of development-specific signaling platforms involved in cell communication. The CWI MAPK cascade (shown in panel B) likely assists in the initial phase of self-signaling. HAM-9 mediates cross-talk between parallel pathways. Phosphorylated MAK-2 is suspected to regulate the accumulation and docking of secretory vesicles containing chemoattractant at the cell cortex closest to the interacting cell. Targeted delivery of chemoattractant vesicles from the Golgi to the release site occurs along the F-actin cytoskeleton. Secretion is regulated via the exocyst, including the protein transporter SEC-22 and the C2-domain protein HAM-10, and probably the exocyst protein SEC-15. The ER-localized ATPase assembly factor PKR-1 is likely to be involved in providing the energy required for vesicle trafficking. Cortical recruitment of HAM-1/SO, a WW domain protein of yet unknown function, occurs out-of-phase with MAK-2, i.e. during MAK-2's refractory period, and might be involved in the rapid release of the super-threshold response signal. The Golgi-localized calcium sensor CSE1 and PI4-kinase PIK-1 are suspected to coordinate chemoattractant release with MAK-2 oscillations, probably in cooperation with the 14-33 domain protein NFH-2. The secreted serine-protease SPR-7 and the histidine kinase NIK-1 are indicated negative regulators of selfsignaling and, for example, may be important to block protein activities during refractory periods of the oscillations. In addition, deactivation of PR MAP kinases through phosphatase PP-2A (here represented by its catalytic subunit PPG-1) is probably important to avoid selfstimulation. 


\section{B - Directional polarized tip growth}

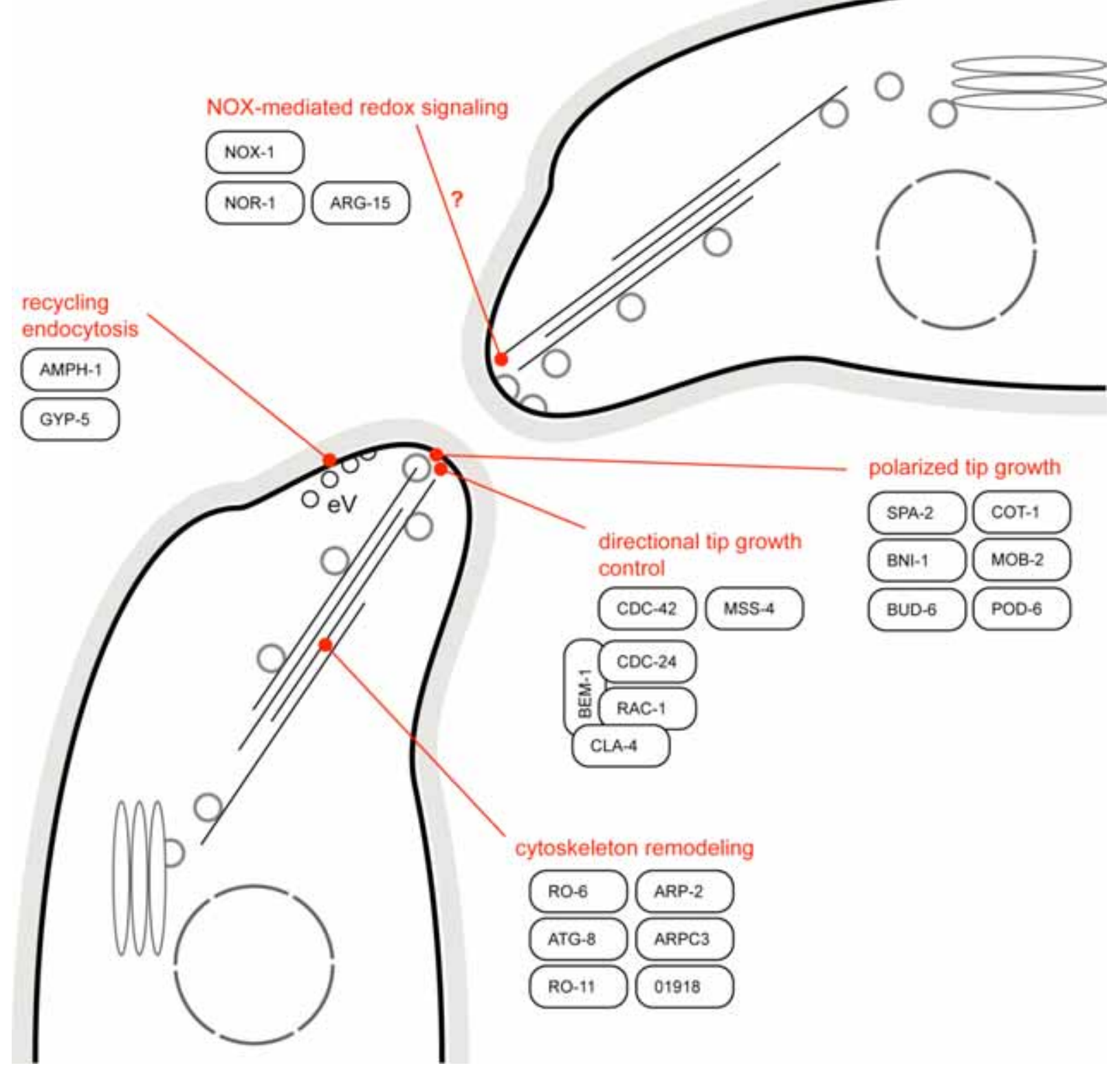

Fig. (1B). Directional polarized tip growth. The smallGTPases CDC-42 and RAC-1, together with their GEF CDC-24, and the polarisome components SPA-2 (polarisome scaffold), BNI-1 (formin) and BUD-6 (actin-binding protein), and in addition to the NDR kinase complex (COT-1/MOB-2/POD-6), are key regulators of general polarized tip growth. The COT-1 complex components have not been found to be essential for cell-cell fusion, but they support cross-talk between involved signaling pathways. Notably, RAC-1 has a specific function for CAT morphogenesis and positive chemotropism. The PI4P 5-kinase MSS-4 also seems essential for polarized tip growth; although its precise function during cell-cell fusion is, so far, unclear. The amphiphysin AMPH-1 is proposed to mediate endosome formation and likely promotes recycling-endocytosis, important to maintain continuous and rapid cell cortex expansion. The GTPase activating protein GYP-5 is indicated to have a minor, yet unclear function as a negative regulator in that process. Chemotropically interacting CATs need to coordinate oscillatory self-signaling with directional tip growth in order to constantly re-orientate their growth towards each other and to achieve cell-cell contact. The scaffolding protein BEM-1 functionally links cell communication with the polarized tip growth machinery through the assembly of a CDC-24/RAC-1/CLA-4 complex at the cell cortex, and by mediating cross-talk to a HYM-1/STE-20/NRC-1 complex (not shown) required for MAK-2 activation. Lateral displacement of both complexes, probably initiated by re-localized RAC-1 GTPase shuttling, reorientates tip growth towards the interaction partner. The dynein intermediate chain 2 protein RO-6, the dynein-associated protein RO-11, and the subunit of the microtubule-associated protein ATG-8 are likely involved in remodeling processes of the cytoskeleton. These functions may be more important during vegetative hyphal fusion, because microtubules are not required for CAT-mediated cell fusion. F-actin is sufficient for CAT function and its dynamic remodeling is controlled through the ARP-2/3 complex. NADPH-oxidase (NOX-1/NOR-1) mediated redox signaling is likely involved in the process; functional details, however, are unknown. The acetylornithine-glutamate transacetylase ARG-15 may have a role in redox detoxification during NOX-mediated signaling.

(?) Question marks indicate unknown protein functions. 


\section{C - Cell wall attachment, fusion pore opening and plasma membrane merger}

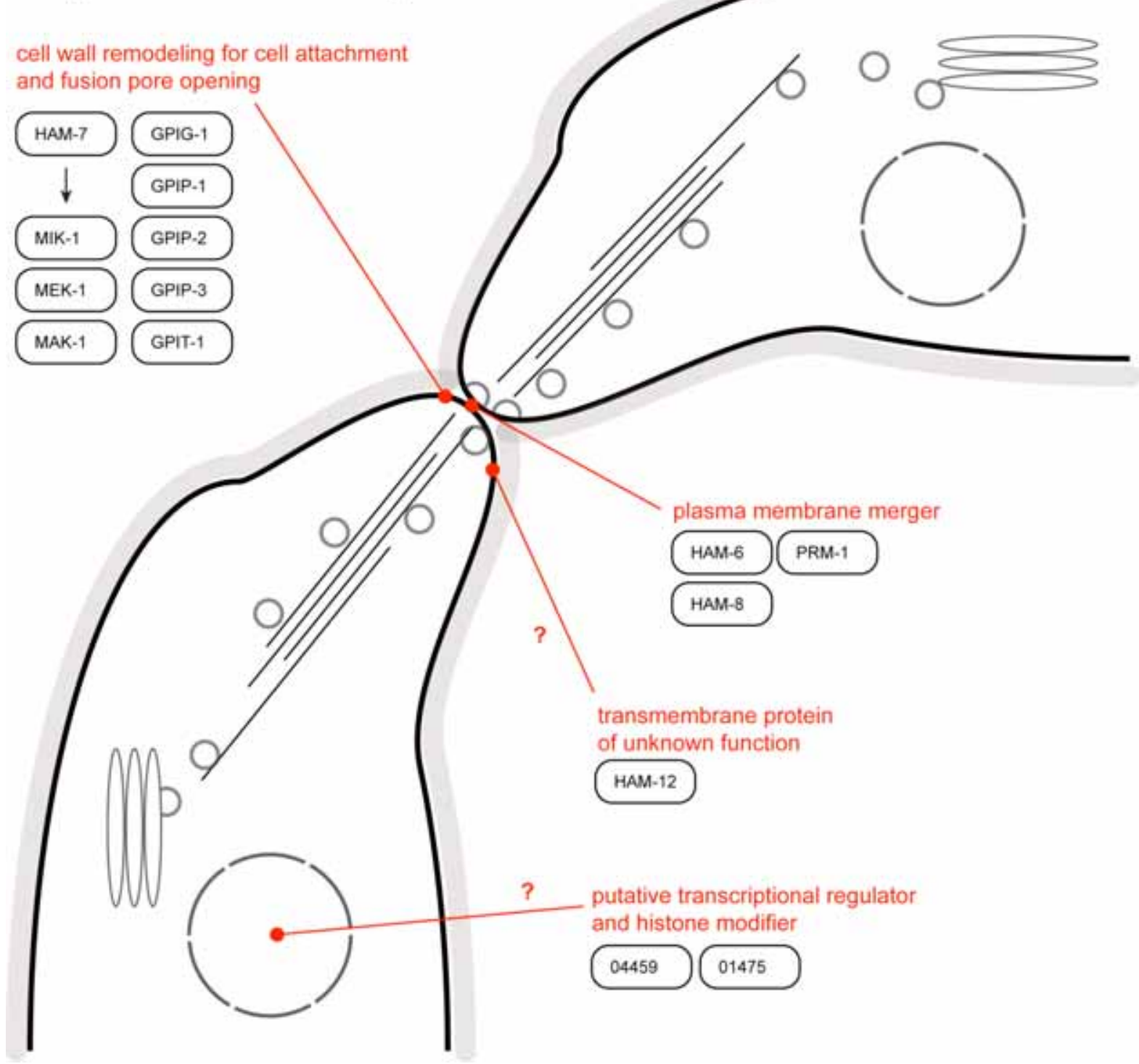

Fig. (1C). Cell wall attachment, fusion pore opening and plasma membrane merger. As soon as chemotropically interacting cells are in physical contact, polarized tip growth terminates and the cells firmly attach by remodeling their cell walls. The glycosylphosphatidylinositol (GPI)-anchored membrane protein HAM-7 has recently been identified as activator of the CWI MAPK cascade, whose components MIK1/MEK-1/MAK-1 are immediately recruited to the incipient fusion site and facilitate firm attachment and fusion pore opening. Another set of GPI-anchored proteins, comprising GPIG-1, GPIP-1 to -3 and GPIT-1, have been implicated in cell wall remodeling during vegetative hyphal fusion. Their role in germling fusion has yet not been investigated, partly due to the aconidiate nature of the corresponding gene deletion mutants. The final stage of cell fusion is plasma membrane merger, which establishes cytoplasmic continuity. Again HAM-7, but also two other putative transmembrane proteins, HAM-6 and HAM-8, as well as the P-type ATPase PRM-1 have been found to be involved in this process. HAM-6 is so far the only candidate protein to act as a bona fide fusogen, i.e. a protein whose exclusive function it is to pull the two plasma membranes together. The complete fusion failure of $\Delta$ ham- 6 germlings supports this notion. Functional details of how PRM-1 and HAM-8 support this process are currently unknown. Three additional proteins of yet unknown function, but with indicated roles in cell fusion are: the predicted transmembrane protein HAM-12; the predicted ROX-3 mediator encoded by locus NCU04459; and the predicted SAGA complex component encoded by locus NCU01475. The latter two are likely to be involved in transcriptional regulation and histone modification, however, further functional details remain to be elucidated.

$[\mathrm{CW}=$ cell wall; $\mathrm{PM}=$ plasma membrane; $\mathrm{N}=$ nucleus; $\mathrm{G}=$ Golgi; $\mathrm{sV}=$ secretory vesicles; $\mathrm{eV}=$ endocytic vesicles $]$

(?) Question marks indicate unknown protein functions.

therefore, appears to be a key integrator molecule that functionally links positive feedback loops of MAK-2 signaling with directional tip growth. Interestingly, BEM-1 did not require physical interaction with MAK-2 for this function. Candidate adaptor proteins, which at the same time could mediate phosphorylation of MAK-2, are the p21activated kinases (PAK) STE-20 and CLA-4. Yeast-twohybrid analyses detected physical interactions of HYM-1 and 
NRC-1 with STE-20, but not with the homologous kinase CLA-4 or MAK-2 [70]. This points to the formation of a HYM-1/STE-20/NRC-1/MEK-2 complex that passes the activation signal onto MAK-2.

Other studies collectively suggest that STRIPAK complexes also function as locally assembled signaling platforms at the plasma membrane. These platforms could coordinate the spatiotemporal recruitment of developmentspecific signal transduction pathways involved in selfsignaling and polarized growth of CAT tips. The phoceinhomolog MOB-3, for instance, is a conserved striatincomplex interacting protein and required for CAT formation and vegetative hyphal fusion in $N$. crassa [80]. In $S$. macrospora the orthologous protein SmMOB3 has also been found to be essential for hyphal fusion [81]. Phenotypic analyses in $N$. crassa furthermore identified the striatin-like protein HAM-3 as essential for germling fusion, which potentially in interaction with calmodulin facilitates the rapid oscillation of MAK-2 and SO by a yet unknown mechanism [71].

Septins are very likely involved in shaping and holding plasma membrane signaling platforms defined through MSS4 and STRIPAK activity in place. CDC-11 has recently been shown to specifically localize to CATs and concentrate around the opening fusion pore, making it a prime candidate for more detailed investigations during oscillatory selfsignaling in $N$. crassa [82]. Functional characterization of individual septins is challenging due to their highly redundant nature and pleiotropic polarity defects of the corresponding gene deletion mutants. Therefore, it is not surprising that significant cell fusion defects could not be observed in septin single gene knock-out mutants so far [82].

F-actin is another essential cytoskeletal component involved in CAT-mediated germling fusion. Chemical disruption of F-actin completely prevented CAT formation and function, whereas inhibition of microtubule polymerization did not significantly affect cell fusion [8385]. The key functions of F-actin in germling fusion are: (i) to provide tracks for the targeted delivery of plasma membrane and cell wall biosynthesis components for directional tip growth, and (ii) to deliver secretory vesicles containing the self-signaling chemoattractant from the Golgi to the plasma membrane for exocytosis during oscillatory cell-cell communication. Therefore, it was not surprising to find that germling fusion was greatly inhibited in mutants lacking ARP2/3 complex components [83].

Structural details and aspects of functional cooperation between the three main cytoskeletal elements, F-actin, microtubules and septins, during different morphogenetic events in $N$. crassa, including cell-cell fusion, have recently been summarized elsewhere [57, 58].

In addition to plasma membrane associated STRIPAK complexes, new data identified a STRIPAK complex associated to the nuclear envelope in mature hyphae of $N$. crassa [39]. Although this study provided compelling evidence for functional connection between nuclear STRIPAK complex and the PR and CWI MAPK pathways, suggesting that MAK-2-dependent phosphorylation of
MOB-3 is part of the MAK-1 nuclear import mechanism, its relevance for oscillatory cell-cell communication between fusing conidial germlings seems unlikely. For two reasons: firstly, nuclear localization of MAP kinases is generally believed to regulate gene expression, however, the signal oscillation period during CAT chemotropism is too fast to be transcriptionally regulated [34]. Secondly, oscillatory selfsignaling between conidial germlings has been shown in this study to occur independently of the nuclear accumulation of MAK-1 [39]. Considering the indicated differences of protein dynamics during chemoattraction between germlings and fusion hyphae, it will be most revealing to test the relevance of the nuclear envelope-associated STRIPAK complex for vegetative hyphal fusion in the mature colony.

\section{OTHER SIGNALING PATHWAYS INVOLVED IN CELL FUSION REGULATION}

NADPH oxidase-dependent redox signaling. The importance of NADPH-oxidase (NOX) signaling for cell fusion has first been recognized in the grass endophyte Epichlö festucae. Loss of hyphal fusion through genetic deletion of components of the NOX signaling complex, including NoxA, NoxR, RacA, Cdc24 and BemA, as well as the newly identified transcriptional regulator ProA, lead to prolific growth of the fungus inside the plant tissue. The changed growth pattern of the fungus switched the mutualistic to an antagonistic interaction resulting in the eventual killing of the host plant [86-89]. The hyphal fusion defects observed in the corresponding mutants are analogous to what has been observed in the orthologous gene deletion strains of $N$. crassa, including dispensability of NoxB/NOX-2 for cell fusion $[72,73,90]$. This clear functional distinction between the two NOX isoforms seems to be conserved amongst filamentous fungi, and in the context of cell fusion, has also recently been reported for CAT-mediated cell fusion in Botrytis cinerea [91]. Whereas BcNOXA was found to be essential for cell fusion but dispensable for pathogenicity, BcNOXB was essential for disease establishment but not required for cell fusion. The fact that germlings growing on the host plant surface did not at all induce CATs, but instead promoted appressorium-formation, provides a likely explanation for the functional diversification of the two NOX isoforms in distinct developmental pathways.

The localization of the NOX complex to apical caps in mature hyphae of E. festucae, has led to suggest a role of reactive oxygen species (ROS) signaling in polarized hyphal tip growth. This however, is contrasted by the fact that polarized growth defects have so far not been observed in these mutants under standard conditions [92]. The functional role of NOX in cell fusion, therefore, is still unresolved, and warrants closer inspection.

Calcium signaling. The most recently emerging regulatory signaling pathway controlling self fusion is calcium signaling. Conducting a genome wide association study, Palma-Guererro et al. [93] identified the calcium sensor CSE-1 and two of its predicted interaction partners, the phosphatidylinositol 4-kinase (PIK-1) and the putative 14-3-3 signaling protein NFH-2, which is believed to shuttle 
PIK-1 between nucleus and cytoplasm, as important players in cell-cell communication between $N$. crassa germlings. Gene deletion mutants in all three proteins showed a reduced fusion frequency compared to the wild type and were unable to recruit MAK-2 or SO to the plasma membrane. The same study, furthermore, reported that mutants lacking components of the exocyst complex, including the protein transporter SEC-22 or the exocyst protein SEC-15, displayed a complete failure of chemotropic interaction. Based on these and other data CSE-1, PIK-1 and NHF-2 have been proposed to be required for calcium-dependent initiation of the oscillatory protein recruitment mechanism, and suggested to act in a joint function with the Golgi secretory pathway [93]. This indicates a role of calcium signaling for the regulation of exocytotic chemoattractant release. Also worth mentioning is that this study for the first time identified negative regulators of CAT-mediated cell fusion. Novel players, including a putative GTPase-activating protein (GAP), the nonidentical kinase NIK-2, and the subtilisin-like protease SPR-7, that when deleted led to an increased fusion frequency compared to the wild type. Identification of their functional roles within the cell-fusion signaling-network awaits detailed characterization.

Physiological significance of cell fusion for fungal development.The accepted assumption is that hyphal fusion allows cooperation and sharing of resources within the colony network, and thus provides a general fitness advantage on natural substrates with heterogeneous nutrient availability [62, 63]. Germling fusion, in the first place, is generally believed to speed up the establishment of a functionally stratified colony network, however, it seems to follow distinct physiological rules during this early stage of development.

Following earlier findings, which showed that CAT fusion occurs at higher frequency in minimal media compared to rich media [94], tryptophan was identified as an inhibitor of germling but not mature hyphal fusion [95]. These findings provide initial evidence that nutrient availability and cell fusion are functionally linked, and furthermore suggest that physiological responses during early and late developmental stages differ. For conidial germlings, high levels of tryptophan (or other amino acids, such as glycine or lysine) in the microenvironment can provide cues for the presence of sufficient nitrogen resources, and consequently might suppress the formation of a germling network intended to share limited resources. In contrast, the almost indefinitely expanding mature mycelium is a considerably greater sink for resources. Consequently, restricting nutrient uptake and distribution by preventing hyphal fusion in the colony would be disadvantageous. Fischer-Harman et al. [95] discussed that the inhibitory effect of tryptophan on germling fusion was not clearly specific because germination was also reduced. However, one needs to consider that conidia of $N$. crassa also germinate by directly producing CATs without forming a germ tube. This naturally leads to a reduction in the population's germination rate in case CAT formation is specifically inhibited.

Nevertheless, neither germling nor hyphal fusion are essential processes. Despite various pleiotropic morphological defects, often including "flat conidiation" and defects during female fruitbody development [67], the majority of fusion mutants are able to propagate asexually. Moreover, the vast majority of fusion mutants, are male fertile and cross with any fertile female mating partner. Notably, $\Delta p r m-1$ is the first identified male sterile, and thus the only female AND male sterile fusion mutant (50\% reduced fusion) currently known [96]. PRM-1 facilitates plasma membrane merger, and is thus universally required during vegetative germling and mature hyphal self-fusion, sexual trichogyneconidium (nonself) fusion, and crozier fusion, however, dispensable for cell-cell communication and chemotropism. This is contrasted by the $\Delta$ ham-4 mutant, which lacks another component of the STRIPAK signaling complex, and although blocked in hyphal self-fusion, is fully capable of sexual nonself-fusion, and was the first male AND female fertile fusion mutant described [71]. Future investigations on these phenotypically contrasting fusion mutants offer great potential for elucidating further details on the physiological role of cell fusion in $N$. crassa.

Despite recent attempts, a direct functional connection between defects in vegetative hyphal fusion and the abortion of protoperithecial development during the sexual phase of the life cycle could not be established [76]. Altered conidiation pattern and defective protoperithecium formation are typical characteristics of fusion mutants and have been suggested to result from the lack of intra-colonial fusion, reducing the cytoplasmic distribution of resources to sites of conidiophore and fruitbody morphogenesis [97]. This "Compromised Redistribution of Resources in Cell Fusion Mutants" hypothesis has recently been confirmed to be much more critical during the germling stage than during mature colony development. In their elegant study, Simonin et al. [98] compared the redistribution of resources through conidial germling and mature hyphal networks between the wild type ( $100 \%$ fusion), the $\Delta p r m-1$ mutant $(50 \%$ reduced fusion; [96]) and the soft mutant (0\% fusion; [35]). Already, the $50 \%$ decrease in fusion competency significantly affected the ability of the $\Delta p r m-1$ colony to distribute nutrients from a heterogeneous food source, and consequently, the unconnected colony of soft was incapable of sharing resources [98]. This data also revealed that no significant reverse translocation from the colony periphery towards the center occurred, suggesting that most nutrients are taken up in the central and subperipheral areas of the colony, and distributed outwards. This is supported by the general observation that in actively growing $N$. crassa colonies the main cytoplasmic flow is directed outwards. Streaming velocity is highly promoted through network formation by vegetative hyphal fusion, indicating an important function for hyphal fusion in the speed of nutrient distribution to the growing perimeter of the colony.

While conidial germlings and undifferentiated (i.e. functionally not stratified) colonies readily shared resources upon self-fusion, differentiation into mature (i.e. functionally stratified) colonies restricted resource sharing, indicating age dependency of this phenomenon [98]. Most interestingly, coinoculated mature colonies of $N$. crassa coming into contact with each other were found not to share any resources, even if they were isogenic. Because of HI responses, which usually prevent cytoplasmic mixing upon hyphal 
nonself-fusion, sharing of resources between heterogenic colonies coming into contact would not be expected. Hyphal avoidance and suppression of hyphal fusion at the colony periphery partly explain this phenomenon, however, are contrasted by the increased rate of hyphal fusion in the colony sub-periphery [38]. Therefore, in overlapping colonies, other yet unknown factors must be involved in preventing inter-colony hyphal fusion and resource sharing.

Following the above-mentioned observation that $\mathrm{HI}$ responses are suppressed in conidial germlings; it might be noteworthy that conidial germlings are also capable of derepressing the fusion block of mature hyphae at the colony periphery [79]. Of further significance in this context is the identification of the germling fusion mutants $\Delta$ ham-3 and $\Delta$ ham-4, which have been reported to be able to resume hyphal fusion in the mature colony [71]. Together these studies highlight that certain physiological functions seem to be exclusive to the germling stage, while others are exclusive to the colony stage. Resource sharing appears to be most important during early developmental stages of colony establishment, whereas at later stages extensive cytoplasmic mixing, including exchange of nuclei, is restricted and probably suppressed.

Richard et al. [99] tested the fitness dynamics associated to fusion. Not surprisingly, germinating conidia of $N$. crassa cultivated at high density benefited from the ability to fuse and showed less competition compared to fusion-defective germlings. Fusion competency further enabled mature colonies to grow larger in plate cultures, whereas a fusion defect promoted quick linear colony extension in race tubes. Depending on the micro-environmental conditions and biology of the fungus the capacity to fuse can thus be both advantageous and disadvantageous.

A similar trend has also been observed in filamentous fungal species with other lifestyles. The gene deletion mutants $\Delta f m k l$ and $\Delta f s o l$ of the plant pathogen Fusarium oxysporum, orthologs of $\Delta m a k-2$ and soft of $N$. crassa, for instance were found to be impaired in network formation on the plant root surface and showed reduced virulence, however, were not impaired in invasive growth once the plant has been successfully colonized [100]. In contrast, $\Delta$ ste 12 of $F$. oxysporum, orthologous to the transcription factor mutant $\Delta p p-1$ of $N$. crassa, was impaired in invasive growth, but not defective in root adhesion or hyphal fusion [101]. Thus, although cell fusion is not essential for host infection per se, it is during the early stages of the infection process, including surface sensing and root adhesion, that a cell fusion defect negatively influenced development of the fungus. This might be connected to the disruption of mitosis and nuclear migration inside germling networks. Although the authors generically talk about fusing hyphae, the morphology of the chemotropically interacting cell protrusions, emerging from conidia and germ tubes of $F$. oxysporum, suggests the presence of CATs in this species equivalent to those defined in $C$. lindemuthianum and $N$. crassa [37, 102, 103]. The nuclear migration and degradation dynamics between donor and receptor cells within the forming germling network show some interesting resemblance with nuclear dynamics and induced autophagy occurring prior to appressorium-mediated host infection by the rice pathogen Magnaporthe oryzae [102, 104]. As the function of this mechanism in $F$. oxysporumis currently unknown, future studies have to test the significance of the observed nuclear dynamics during germling fusion for F. oxysporum virulence in planta.

A link between cell fusion and virulence of $F$. oxysporum has recently been established in the context of metabolic control. Ammonium nitrate dramatically reduced the extent of hyphal fusion in this species, an effect that was inversed or suppressed in gene deletion mutants of two transcription factors controlling nitrogen metabolite repression [105]. Because ammonium negatively regulates vegetative hyphal fusion and root adhesion, presence of this nitrogen source significantly delayed infection in the positive transcriptional regulator mutant $\Delta$ area. Repression of invasive growth by ammonium was found to be conserved in two other plant pathogens, Fusarium graminearum and M. oryzae [105]. However notably, in contrast to $F$. graminearum [106], hyphal fusion has not been observed in M. oryzae (Lichius, A., unpublished observation). Germling fusion in the bean pathogen Colletotrichum lindemuthianum [107], is fully inhibited by nutrients and only occurs in water, which resembles the conditions on the host plant leaf surface [108]. Still, whether a direct functional correlation between germling fusion and host infection by Fusarium spp. or Colletotrichum spp. exists, or whether reduced virulence is an indirect pleiotropic effect of the fusion defect, awaits further clarification. The same is true for the cruciferous pathogen Alternaria brassicicola. Notably, germling fusion is absent from this species, but A. brassicicola mutants lacking the $N$. crassa SO and MAK-2 orthologs, asol and amk1, are unable to undergo vegetative hyphal fusion which correlated with the loss of virulence on the host plant [109, 110]. The failure to sustain a progressive infection of the asol mutant has been suggested to result from the inability to efficiently translocate nutrients, signaling molecules or necrotic toxins between fungus and host plant [109].

Another recent study looked at below ground germling network formation between symbiotic and nonsymbiotic arbuscular mycorrhizal hyphae. Germlings of Glomus mosseae are capable of establishing fusion connections to symbiotic, extraradical hyphal networks already in contact with the host plant [111]. This offers young germlings quick access to plant-derived nutrient sources before nonsymbiotic growth arrest prevents their survival. Interestingly, HI reactions between genetically dissimilar fungal isolates were readily observed in the form of plasma withdrawal even before cell-cell contact and fusion had occurred. Subsequent cytoplasmic mixing was furthermore effectively prevented through the formation of retraction septa immediately after fusion. Nonself recognition leading to HI responses, therefore, seems to occur pre-fusion in this species, and must involve diffusible signaling substances that prevent nonselffusion altogether. The physiological significance of cell fusion in this scenario appears to be classic symbiosis: the more fusion connections within the fungal network can be established, the better the plant grows. Elucidating genetic determinants and molecular pathways of this self-fusion mechanism in arbuscular mycorrhizal fungi promises to develop into an exciting research area.

Overall, a universally valid conclusion on the physiological significance of cell fusion for filamentous 
fungal development cannot be drawn. Its biological function is too diverse and highly dependent on the individual lifestyle of the species. Obviously, more research needs to be directed towards the identification of those species where an intervention of germling and hyphal fusion can disrupt fungal development and thus be applied for the protection of crop plants and human health.

\section{CHEMOATTRACTION FOR SEXUAL REPRO- DUCTION}

The key event for sexual reproduction in ascomycetes is the formation of the dikaryon. The aggregation of two parental haploid nuclei in one cellular compartment is a prerequisite for nuclear fusion (karyogamy) leading to the constitution of a short-lived diploid cell that produces meiotic progeny in the form of homokaryotic ascospores. Two basic sexual lifestyles can be distinguished in filamentous fungi that achieve dikaryon formation in two fundamentally different ways, and therefore have different requirements towards chemoattractive mechanisms: heterothallism and homothallism. Heterothallic species are self-incompatible (self-sterile). They depend on outcrossing, that is the interaction between two opposite mating-type gametes, which each contribute one nucleus to the dikaryon, thus forming a heterodikaryon. For sexual reproduction, heterothallic species generally use a bilateral sexpheromone/cognate-receptor system to control nonself chemoattraction and establish nonself-fusion between male and female partner. On the genetic level, sexual identity is regulated through different mating type loci, and fertilization is achieved through transfer of a male nucleus to the female.

In contrast, homothallic species are self-compatible (selffertile), and do not require an opposite mating-type partner for sexual reproduction. They commonly lack specific hyphae for sexual nonself-fusion, and consequently, homothallic species are able to produce meiotic progeny autonomously by forming a homodikaryon after recruiting two genetically identical nuclei from the vegetative mycelium into one cell compartment. Whether formation of a homodikaryon requires a fusion event at all, or is accomplished by other means, such as septation, is still not resolved. The following sections will explore key features of heterothallism and homothallism, and also exemplify reproductive systems that do not fit into this simple classification. Fig. (2) provides a shematic overview on the discussed reproductive strategies of filamentous ascomycetes.

Sexual chemoattraction in the heterothallic fungus Neurospora crassa. Neurospora crassa is a bona fide heterothallic, obligatory outcrossing species in which the morphological and molecular details of the sexpheromone/cognate-receptor-based nonself recognition system are very well characterized. Under carbon- and nitrogen-limiting conditions the vegetative mycelium of $N$. crassa enters the sexual phase by autonomously differentiating ascogonial coils, which continue development to the protoperithecial stage in the absence of an opposite mating partner [112]. Although cell fusion mutants of $N$. crassa are blocked at these early stages of female fruitbody (ascogonial and protoperithecial) development, it is still unclear whether self-chemoattraction and self-fusion are required for ascogonial coil or protoperithecium morphogenesis [76]. Protoperithecia send out specialized hyphae (trichogynes) that chemotropically grow towards cells of the male (often asexual macroconidia; occasionally microconidia) and establish cytoplasmic continuity by nonself-fusion [113, 114]. For this, the male cell secretes a mating-type-specific peptide sex pheromone that is recognized by its cognate GPCR on the surface of the opposite mating-type trichogyne, guiding the trichogyne's directional growth $[47,48]$. Trichogynes of one mating type will, therefore, only be attracted to and fuse with male cells of the opposite mating type. It appears that trichogynes do not produce pheromones and male cells do not express cognate receptors. Consequently, deletion of sex-pheromone genes only leads to male sterility, whereas deletion of pheromone-receptor genes only leads to female sterility $[115,116]$. Nonself recognition and chemotropic growth in this interaction, therefore, is a unilateral event because it is exclusively executed by the trichogyne. The male cell is only required to produce and release sex pheromone, but otherwise has a very passive role. Upon trichogyne-male cell nonself-fusion, male nuclei from the macroconidium migrate through the trichogyne to the ascogonium, the female gamete located inside the protoperithecium [35]. Here plasmogamy takes place, which is the moment when one male nucleus joins up with one female nucleus in the shared cytoplasm of the ascogenous hyphal-tip-cell compartment, which from that moment constitutes the heterodikaryon. Heterodikaryon formation is maintained through prototypic, tricellular crozier fusion [117], in which the terminal cell containing one "daughter" male nucleus grows back and fuses with the subtending cell compartment of the ascogenous hyphae allowing the next set of male and female nuclei to pair up. Subsequent karyogamy (fusion of female and male nuclie) completes fertilization and forms the short-lived diploid ascus-mother-cell, which immediately progresses through meiosis and ascosporogenesis. Successful fertilization results in the production of ascospores.

It is important to note that the definition of fertilization is not conserved amongst filamentous species. Our definition of fertilization is based on observations in N. crassa, and comprises a series of four key events temporally and spatially separated: (i) presentation of the male cells to the female, which is widely described by mycologists as "fertilizing a culture", (ii) nonself-fusion between female trichogyne and male cell (e.g. macroconidium), followed by transit of male nuclei into the female fruitbody, (iii) plasmogamy, leading to heterodikaryon formation inside the ascogonium, and (iv) karyogamy, starting point of the generation of meiotic progeny. Notably, for dikaryon formation and subsequent production of meiotic progeny to occur, plasmogamy and karyogamy are always required, no matter what the morphological and mechanistic differences between species might be.

Investigations during heterothallic sexual reproduction in the pseudohomothallic $P$. anserina (see below) have shown that crozier formation does not depend on sex pheromones [49], strongly suggesting that crozier fusion can be classified as a self-fusion event. We are not aware that this mechanism has been experimentally investigated thus far in $N$. crassa, however, it is very likely to result in the same finding. Already 


\section{Reproductive Strategies of Filamentous Ascomycetes}

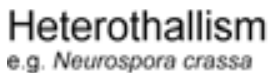

e.g. Neurospora crassa

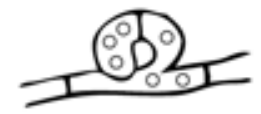

ascogonial coil develops from HOMOKARYOTIC

vegetative mycelium

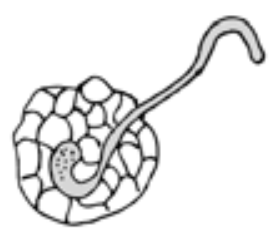

protopenthecium USUALLY differentiates trichogynes

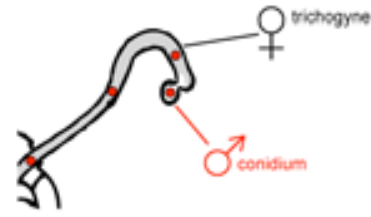

protoperithecium-to-perithecium transition requires NONSELF FUSION with an opposite mating-type male cell: male nuclei travel through trichogyne into female ascogonium

\section{Homothallism}

e.g. Sordaria macrospora

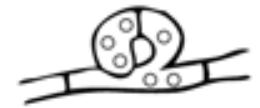

ascogonial coil develops from HOMOKARYOTIC vegetative mycelium

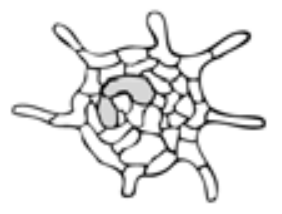

NO EVIDENCE for trichogyne formation from protoperithecia

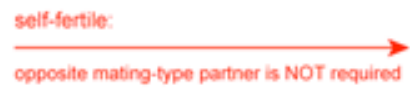

protoperithecium-to-perithecium transition occurs AUTONOMOUSLY

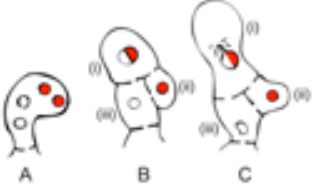

HETERODIKARYON is formed inside the perithecium by combining nuclei of opposite mating type (male and female) through crozier formation and cell fusion

\section{Pseudohomothallism e.g. Podospora anserina}

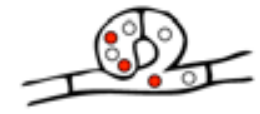

ascogonial coil develops from HETEROKARYOTIC vegetative mycelium

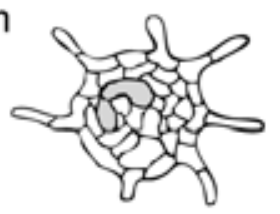

protopenthecium does NOT COMMONLY differentiate trichogynes

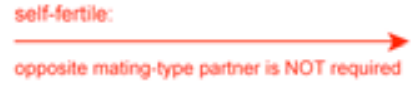

protoperithecium-to-perithecium transition occurs AUTONOMOUSLY

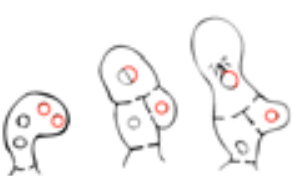

HOMODIKARYON is formed inside the perithecium by combining genetically identical nuclei through crozier formation and cell fusion; nuclei are functionally distinct due to differential mating-type gene expression (FUNCTIONAL HETERODIKARYON)

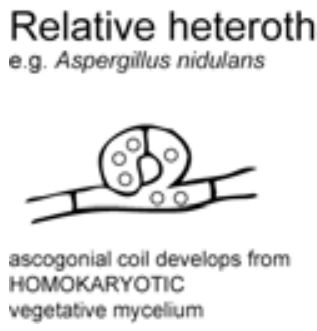

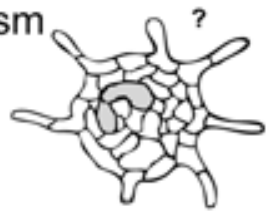

NO EVIDENCE for trichogyne formation from protoperithecia

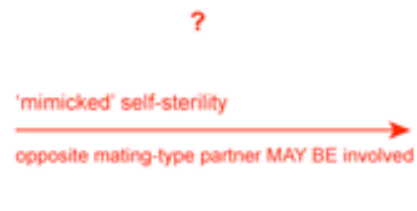

morphogenetic details of protoperithecium-to-perithecium transition UNKNOWN

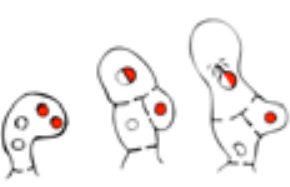

HETERODIKARYON is formed inside the perithecium by combining two nuclei of opposite mating type through crozier formation and cell fusion

\section{Fig. (2). Reproductive strategies of filamentous ascomycetes.}

Heterothallism. $N$. crassa develops an ascogonial coil from the homokaryotic, vegetative mycelium, which therefore contains isogenic, female nuclei (indicated as black circles). The ascogonial coil constitutes the female ascogonium (indicated in light grey) in the center of the maturing protoperithecium, and sends out trichogynes, which connect it to the external environment. Nonself-fusion between female trichogyne and male conidium allows male nuclei (indicated as red circles) to travel into the ascogonium. Crozier formation and cell fusion lead to heterodikaryon formation: depiction of Raju's micrographs from 1980 using the 2003 terminology of Bistis et al. [231, 232]. According to Raju, the binucleate penultimate cell (i) of the three-celled crozier grows into an ascus, whereas the terminal crozier cell (ii) fuses with the basal crozier cell (iii). (A) shows the crozier beginning to form, with the hyphal tip curling around. (B) illustrates heterodikaryon formation in the penultimate crozier cell (i); septation between the penultimate crozier cell (i) and the terminal crozier cell (ii); septation between the penultimate crozier cell (i) and the basal crozier cell (iii); and also a fusion pore is depicted between the terminal crozier cell (ii) and the basal crozier cell (iii). (C) shows a slightly later stage where the penultimate crozier cell is going through the shortlived diploid stage prior to meiosis. The fusion between the terminal and basal cells enable nuclei from these cells to come together and, after mitosis, form the next crozier, thus perpetuating the formation of asci. Similar drawings and descriptions have illustrated this in other Sordariomycetes, e.g. S. macrospora [233, 234]; P. anserina [160]. 
Homothallism. S. macrospora also forms ascogonial coils from the homokaryotic, vegetative mycelium, which develop into protoperithecia. Protoperithecia of $S$. macrospora, however, have never been shown to develop trichogynes and do not require interaction with an opposite mating-type male partner. Perithecia develop autonomously. Dikaryon formation inside the ascogonium likely takes place by a self-fusion or septation event, and due to the isogenic nature of all nuclei theoretically leads to the formation of a homodikaryon. Nevertheless, differential gene expression generates distinct sexual identities between nuclei (indicated as black and red circles) and consequently establishes a functional heterodikaryon.

Pseudohomothallism. $P$. anserina forms ascogonial coils from a heterokaryotic, vegetative mycelium, i.e. nuclei of distinct genotypic makeup are already combined in a shared cytoplasm. Further sexual development occurs similar to that of a homothallic species, such as $S$. macrospora, but leads to the formation of 'true' heterodikaryons inside the ascogonium. Notably, $P$. anserina is also capable of generating homokaryotic isolates from the heterokaryotic mycelium by separating opposite mating-type nuclei into male microconida and female ascogonia. Female trichogynes emerging from resulting protoperithecia, then exclusively engage into nonself-fusion with opposite matingtype male microconidia.

Relative heterothallism. A. nidulans forms ascogonial coils from a homokaryotic, vegetative mycelium. Trichogyne formation has, so far, not been observed in developing protoperithecia embedded in cleistothecial primordia, but cannot be excluded either. Especially in those cases where heterogenic, homokaryotic individuals cross. Morphogenetic details of such an interaction are not known, therefore, it currently remains uncertain whether dikaryon formation occurs as in facultative hetero- or homothallic species, and would lead to the formation of a "true" or "functional" heterodikaryon.

(?) Question marks indicate unknown morphologies.

in 1992, Raju pointed out that little was understood about the behavior of nuclei from the point of completed male celltrichogyne fusion until the formation of the heterodikaryon in Neurospora and other well-studied filamentous ascomycetes [118]. Since then, numerous studies on postfertilization events and ascospore development, have significantly contributed to our understanding of the genetic control of sexual development in ascomycetes, and have been extensively reviewed elsewhere [119, 120]. Nevertheless, our insights into the regulatory role and mode of nuclear transport during the early fertilization stages (trichogyne-male cell fusion, male nuclear transit and crozier maintenance) are still sparse.

Sex-pheromone precursor genes and pheromone-receptor genes are usually not transcribed in a strictly mating-typedependent manner. Thus, mating-type identity is determined through enhanced expression of one of the two sexpheromone and pheromone-receptor genes, respectively. In $N$. crassa, for instance, mating-type mat a cells express high levels of the CCG-4 pheromone that is recognized by the PRE-1 receptor of mat $A$ trichogynes, and conversely, mat $A$ cells highly express the MFA-1 pheromone, which is the ligand of the PRE-2 receptor of mat a trichogynes [47, 48, $114,115]$. This duplicate system of two exclusively matching sex-pheromone and cognate-receptor pairs prevents self-attraction and guarantees self-sterility. Furthermore, it allows each mating type to act as female AND male, increasing the chance of successful sexual reproduction in nature. Most interestingly, in a recent study this nonself chemoattraction system has been experimentally overridden by co-expression of CCG-4 (mat a pheromone) and PRE-2 (mat a GPCR) in a $\Delta$ pre-1 mat $A$ background, forcing self-attraction and auto-fusion of trichogynes [115]. However, despite this atypical interaction, sexual development did not proceed beyond the stage of mature protoperithecia, confirming that a functional sexpheromone/cognate-receptor system alone is insufficient for successful sexual reproduction in an exclusively heterothallic species. Another interesting locus in this context is female and male fertility 1 ( $f m f-1)$. FMF-1 is a key regulator of both the expression of pheromone receptors in trichogynes and the synthesis and secretion of male pheromone by conidia.
In $\Delta f m f-1$ strains perithecial development arrests either as male OR female [121, 122]. To our knowledge, thus far, this is the only locus described that is capable of inducing this behavior when genetically removed.

As mentioned at the beginning of this section, dikaryon formation is the key event during sexual reproduction. Programmed cell death, as the result of vegetative heterokaryon incompatibility (HI; discussed above), therefore, seems to pose a serious problem for heterodikaryon formation in $N$. crassa, in which the matingtype genes (mat $A$ and mat $a$ ) also act as het genes during vegetative hyphal nonself-fusion [123, 124]. In heterothallic fungi, the mating-type genes also function as master-control genes for events leading to successful fertilization [118]. One of their functions is to establish nuclear identity, that is to discriminate self and nonself nuclei within the syncytium established by trichogyne-male cell fusion, and has been researched and reviewed in $N$. crassa and $P$. anserine [25, 125-127]. It has been hypothesized that mating-type-specific and locally confined expression of pheromone and pheromone receptors in the vicinity of paired heterogenic nuclei is involved in nuclear recognition inside the forming heterodikaryon (reviewed [128]). The problem of forming a stable heterokaryon for sexual reproduction in a mycelium that usually is heterokaryon incompatible is thereby solved through development- and tissue-dependent gene regulation. Mating-type-dependent heterokaryon incompatibility in $N$. crassa is mediated by the tol locus, which is suspected to form a death-triggering complex (similar to the HET-C/PINC complex) with MAT A-1 or MAT a-1, or other downstream products [129]. Following nonself-fusion between trichogyne and male cell, tol expression, and consequently HI, is suppressed allowing the coexistence of opposite mating-type nuclei in sexual reproductive structures of the fungus [129]. This phenomenon is reminiscent of the transient suppression of HI during conidial germling selffusion discussed in the previous section. The mid-line or junction zone is a known phenomenon describing the area of PCD that is found between the two lines of fertile perithecia produced by each crossing partner, but not in the locally confined region where sexual reproduction takes place. It is, therefore, a visible marker for tissue-dependent gene 
regulation allowing HI being exclusively suppressed in the area of the mycelium where sexual reproduction takes place.

In summary, $N$. crassa is a representative model for true, obligate heterothallic species, which use a molecularly and structurally elaborate system to ensure that sexual reproduction can only occur between opposite mating-type partners. This includes a duplicate, bilateral sexpheromone/cognate-receptor system, the differentiation of female fruitbodies and specialized sexual fusion hyphae (trichogynes) for their fertilization. An elaborate genetic system for the determination of sexual identity, and tissuespecific suppression of heterokaryon incompatibility are key regulatory elements in this.

Sexual chemoattraction in the homothallic fungus Sordaria macrospora. Sordaria macrospora is a model representative of a homothallic, self-fertile species. Protoperithecial, perithecial and ascospore development occur autonomously and continuously from the vegetative mycelium [130]. In contrast to $N$. crassa, S. macrospora does not form trichogynes or conidia, excluding the possibility of achieving fertilization and dikaryon formation by fusion between these two cellular elements. Consequently, it would appear that $S$. macrospora has no use for a bilateral sex-pheromone/cognate-receptor system as it is used by heterothallic species to regulate nonself-fusion for fertilization. Surprisingly however, S. macrospora does express two sex-pheromone precursor genes (ppgl and ppg2) and two cognate-receptor genes (pre1 and pre2), structurally similar to those of $N$. crassa [51, 131, 132]. Notably, single gene deletion mutants of these four loci showed no impairment in sexual reproduction. Doubleknockout strains lacking any compatible pheromone-receptor

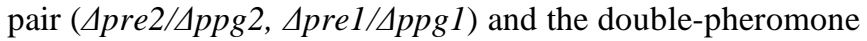
mutant ( $\triangle p p g 1 / \Delta p p g 2)$, however, displayed a drastically reduced number of ascospore-producing perithecia, whereas deletion of both receptor genes (Apre1/Apre2) completely eliminated fruitbody and ascospore formation [131]. These results show that sex pheromones and sex-pheromone receptors are indeed required for optimal sexual reproduction in the homothallic $S$. macrospora.

The hallmark of self-fertility is that individual nuclei contain the same genetic information of both mating types, i.e. are isogenic. The mating-type locus of $S$. macrospora contains a chimeric form of counterparts of sordariomycete MAT genes MAT1-1-1, MAT1-1-2, MAT1-1-3 and MAT 12-1 [132-135], which poses the question whether the homothallic nuclei could be functionally heterothallic [134, 136]? It has already been hypothesized that homothallic ascomycetes could have evolved a mechanism that allows alternate expression of either mating type prior to nuclear migration into the relevant crozier cell and subsequent dikaryon formation [132]. Molecular details of the mechanism remain to be uncovered. Nevertheless, together these data support earlier assumptions that in homothallic species mating-type genes, sex pheromones and cognatepheromone receptors function exclusively in nuclear recognition, the promotion of crozier formation and stabilization of the homodikaryon, or maybe more precisely "functional heterodikaryon". Further support for this notion comes from functional genomic comparison, which clearly showed that key components of cell signaling pathways required to regulate these events are highly conserved in $S$. macrospora. For instance, upon pheromone-receptor activation, downstream signal transduction occurs analogous to the GPCR/MAPK-signaling pathways known from other ascomycete model fungi, including $\mathrm{G} \alpha$ proteins, PR pathway MAP kinases and the transcription factor STE12/PP-1 [137, 138]. Nevertheless, how the initial (homo)dikaryon is being formed inside the ascogenous tissue of the mature protoperithecium of $S$. macrospora, and whether this involves hyphal fusion, has still not been resolved.

Another line of evidence puts emphasis on the role of septation during sexual development of $S$. macrospora. It has been demonstrated, that once nuclei have paired up within the tips of ascogenous hyphae, the (homo)dikaryon is maintained by typical crozier fusion and regulated septation [139]. Furthermore it has been shown, that sexual development in the $S$. macrospora pro22 mutant is arrested at the protoperithecial stage, and coincides with aseptate ascogonia [140]. Because septum formation proceeds normally in the vegetative mycelium, the aseptate phenotype of pro22 is tissue specific for sexual development [140], suggesting that homodikaryon formation through compartmentalization of two genetically identical nuclei by septation might be the inductive fertilization signal for protoperithecium-to-perithecium transition in S. macrospora. Unfortunately, equivalent to its homologous mutant of $N$. crassa (4ham-2) [36], pro22 of S. macrospora also has a vegetative hyphal fusion defect, which also could be responsible for the arrest in sexual development. Ongoing research is attempting to resolve this issue.

Sordaria macrospora is a facultative homothallic; essentially, heterokaryon formation is possible by vegetative nonself-fusion that can lead to recombinant reproduction. For example in confrontation crosses between two individuals, in which perithecia produced by selfing can be clearly distinguished from recombinant ones by their location on the plate. Recombinant perithecia form exclusively in the contact zone of the two mycelia. This is in contrast to selfed perithecia that only appear on one side. Formation of recombinant perithecia can complement genetic defects from two independent sterile mutants [141], but is reduced between fusion-impaired mutants [142]. This confirms that the process does involve vegetative nonselffusion. Heterokaryon incompatibility phenotypes (including a PCD junction zone) have not been observed in $S$. macrospora, nevertheless, homologues of het genes that are found in other fungi have been identified in its genome [132, 137]. Nowrousian et al. [137] found that for het-c, pin-c, and a tol-related HET domain genes, two closely related copies for each of these genes were present in the $S$. macrospora genome, and suggested that heterokaryon incompatibility in $S$. macrospora may be attenuated because of mutations in critical heterokaryon incompatibility-mediating loci, allowing the presence of otherwise incompatible genes within one genome.

In summary, homothallism of $S$. macrospora therefore seems to be a reproduction strategy that has sacrificed 
propagation through vegetative, asexual spores for the ability to reproduce sexually independently of an opposite matingtype interaction partner. It is generally believed that heterothallism is the ancestral system [143, 144], and that homothallic breeding may be a reproduction strategy that facilitates sexual reproduction in a harsh environment, in analogy to what has been suggested for homothallic lichenfungi [145]. The latest review covering these aspects and other essentials of the $S$. macrospora reproductive cycle has been provided elsewhere [146].

The chemoattraction system in the newly discovered sexual cycle of the heterothallic fungus Trichoderma reesei. Trichoderma reesei is another heterothallic species with a bilateral sex-pheromone/cognate-receptor system that has only very recently been discoverd [147, 148]. Similar to $N$. crassa, transcription of the a-type pheromone gene hppl is elevated in MAT1-1, whereas the $\alpha$-type pheromone ppg 1 is expressed at higher levels in MAT1-2 [148]. Transcript levels of the cognate GPCR-type receptors (HPR1 in MAT11 and HPR2 in MAT1-2) are regulated accordingly, together allowing sexual identity determination. In line with previous findings in S. macrospora [131] and $N$. crassa [115], one compatible pair of pheromone and cognate receptors is necessary and sufficient for sexual reproduction in $T$. reesei [148]. The double set of sex pheromones and cognate receptors, therefore, allows both mating types to act as male and female, multiplying the chance of successful sexual reproduction in a natural environment where encountering mating partners is a rare event. The second pheromone/receptor pair of each mating type, although not highly expressed and non-essential for fertilization, however, does have an important function for the initiation of fruitbody development. In $T$. reesei this was shown using crosses between single gene deletion strains that had only their mating-type-specific receptors removed: $\Delta h p r l$ in MAT1-1 and $\Delta h p r 2$ in MAT1-2. In these crosses, ascospores were not produced indicating failed fertilization, but stroma and perithecium formation remained functional [148]. Furthermore, receptor double deletion mutants were, as expected, unable to induce fruitbody formation.

Notably, the HPP1 pheromone of $T$. reesei has an unusual domain structure not known from other fungi, combining characteristics of both a- and $\alpha$-type pheromone precursors [149]. Yet, within this hybrid-type pheromone domain configuration, only the threefold CAAX motif was required for sexual reproduction. Initial evidence, presented in the same study, furthermore, indicated differences in the specific transcriptional regulation of sex-pheromone and cognate pheromone-receptor genes in T. reesei, compared to other heterothallic ascomycetes. Whether this apparently less stringent transcriptional control of pheromone precursors and receptors, in combination with the specific domain structure of the hybrid pheromone, has any functional significance remains to be explored. Further reading about sex-specific pheromone expression in various heterothallic and homothallic fungal species can be found elsewhere [150].

Culture conditions under which $T$. reesei would induce fruitbody development autonomously have so far not been identified, and may not exist. Simple carbon and nitrogen limitation that serve as inductive signals for a number of other ascomycetes do not seem to work. This might be connected to the more complex arrangement of $T$. reese $i$ protoperithecia inside stromata. As described above, $N$. crassa, for instance, generates protoperithecia directly off the vegetative mycelium. The only known way to induce stroma and protoperithecium formation in $T$. reesei is by confrontation of opposite mating-types on the same culture plate and under the influence of light $[147,149,151]$. This might indicate that nonself-signaling between mating partners provides the inductive signal for entry into the sexual cycle. Nevertheless, molecular details of stroma and protoperithecium development, fertilization and continued differentiation into perithecia are currently unknown. Microscopical examination of stroma sections did not provide any evidence for the presence of trichogyne-like structures in $T$. reesei [148], and so far there has been no published evidence for vegetative hyphal fusion occurring in this species.

We are only at the beginning of understanding sexual development in $T$. reese $i$, and one of the next important steps, therefore, will be to identify the mechanism of fertilization in $T$. reese $i$ and how this triggers the protoperithecium-to-perithecium transition inside the stroma tissue.

Alternative mating systems of filamentous fungi. Besides the two main classifications, heterothallism and homothallism, other forms of mating systems have been defined (for a recent review see [152]). These include "pseudohomothallism" (sometimes referred to as "secondary homothallism") and "relative heterothallism", which are discussed here in order to propose that their classifications as distinct might be inappropriate due to the lack of detailed knowledge about the involved morphologies and genetics.

Neurospora tetrasperma and $P$. anserina are the best studied examples of pseudohomothallic species [153]. Their distinguishing key feature, in comparison to "true" heterothallic and homothallic species, is the constant maintenance of the heterokaryotic state, allowing the vegetative mycelium to be self-fertile, and thus apparently homothallic [127, 154, 155]. Similar to "true" homothallic species, dikaryon formation in a self-fertile pseudohomothallic species will require a self-fusion (or potentially a septation) event, but in contrast produces a heterodikaryon. In addition, both species also form uni- and bi-nucleate sexual and asexual spores of a single mating type, which generate homokaryotic individuals that are functionally heterothallic, and outcross with an opposite mating-type partner equivalent to a "truly" heterothallic species $[154,156]$. In this scenario, nonself chemoattraction and nonself-fusion between female and male are required for heterodikaryon formation. It has been demonstrated that heterothallic reproduction in $N$. tetrasperma and $P$. anserina involves trichogyne-male conidium fusion guided by a classical, bilateral sex-pheromone/cognate-receptor non-self recognition system, and that maintenance of the dikaryon is achieved by crozier formation [49, 157-160]. Interestingly, in P. anserina the trichogyne is sent out directly from the ascogonial coil to fuse with a microconidium and trigger protoperithecium development [159]. Hence, at a much 
earlier developmental stage as, for example in $N$. crassa, where trichogynes also may differentiate directly from the ascogonial coil, but usually do not fuse with male cells before protoperithecium maturation is completed [76, 114]. It has also been shown that crozier formation in $P$. anserinadoes not depend on sex pheromones, indicating that it is a self-fusion event [49]. Notably, self-fertility can be genetically re-engineered in heterothallic $P$. anserina strains through deletion of specific mating-type loci that control internuclear self- and nonself recognition prior to dikaryon formation [161]. Interestingly, the opposite (i.e. conversion of a heterokaryotic parent into a self-sterile, homokaryotic strain through manipulation of the MAT genes) was achieved in A. nidulans (see below) [144]. Pseudohomothallism, therefore, is a reproductive strategy that combines the advantages of quick, mating partnerindependent selfing with the potential of genetic recombination through facultative outcrossing.

The percentage of homokaryotic ascospores formed by $P$. anserina and $N$. tetrasperma has so far been estimated at $4 \%$ and $10 \%$, respectively $[154,162]$. The recent comparison of more than $100 \mathrm{~N}$. tetrasperma isolates from the UK and New Zealand, however, revealed that the percentage of selfsterile, homokaryotic conidia can be much higher, up to $42 \%$ [163]. Hence, the proportion of outcrossing individuals in nature is much higher than previously anticipated. The genetic basis of pseudohomothallism has been well researched in the past decade and is most notably achieved through suppressed recombination on the mating-type chromosome [164-167]. The cytology of heterodikaryon formation during selfing, however, is still unresolved, and thus might warrant a closer inspection. Although functional trichogyne-conidium interactions have been confirmed in homokaryotic $N$. tetrasperma strains, the few trichogynes that have been formed from heterokaryotic strains did not respond chemotropically to conidia, and might thus be regarded non-functional [158]. Therefore, it seems possible that heterodikaryon formation in heterokaryotic mycelia of $N$. tetrasperma and $P$. anserina may occur by vegetative self-fusion or simple septation only, similar to what is suspected for homodikaryon/functional heterokaryon formation in the homothallic $S$. macrospora discussed earlier. Finally, it has to benoted that pseudohomothallism is thought to have arisen independently in diverse fungi, including $P$. anserina and $N$. tetrasperma; hence the genetic and cellular mechanisms of pseudohomothallism may differ substantially [168].

The term "relative heterothallism" has been coined to describe the observation of favored mating between genetically different individuals of the generally homothallic species A. nidulans [169]. Relative heterothallism has also been described for the plant pathogenic Glomerella cingulata [170], and assigned to S. macrospora [171]. For $S$. macrospora, however, we are not aware of any published work supporting this claim. In A. nidulans, this mimicked self-sterility leads to the production of recombinant ascospores through outcrossing [169, 172], and has the likely evolutionary benefit of generating recombinant progeny with increased fitness. It has been proposed that a "selection arena" mechanism operates to promote continued development of only high-quality (hetero)dikaryons into sexual spores [173]. Initial dikaryons with deleterious cytoplasmic (viruses, plasmids or abnormal mitochondria) or nuclear mutations are negatively selected, and their development becomes aborted. Earlier investigations in A. nidulans, showing that the number of recombinant progeny emerging from such an interaction correlates with the degree of genetic differences between both mating partners, already suggested that a distinct genetic program acting on the level of nuclear recognition and nuclear sorting within the heterokaryon has to regulate this phenomenon [174]. Further underlying genetic and molecular details of this mechanism, however, have long remained enigmatic.

The identification and manipulation of distinct matingtype genes in $A$. nidulans, leading, for example, to the successful generation of heterothallic $\triangle M A T 1$ and $\triangle M A T 2$ transformants from a homothallic parental strain $[144,175$, 176], provided the first experimental evidence to verify this hypothesis, and to suggest that differential gene expression is the basis of "relative heterothallism". These results indicate that differential expression of mating-type genes, and other genes required for nuclear recognition, generate functionally dissimilar nuclei on the level of transcription (RNA) and protein biosynthesis. This functional nuclear distinction appears to be sufficient for the constitution of a "functional heterodikaryon", despite potential genetic identity of both nuclei on the genomic (DNA) level. As discussed for the homothallic $S$. macrospora earlier, a key role in nuclear recognition and karyogamy in A. nidulans again take sex pheromones and cognate pheromone receptors, which on the other hand, have no function in chemoattraction prior to fertilization due to the apparent lack of differentiated male and female sexual fusion structures, such as trichogynes [177]. Thus, it is conceivable that "relative heterothallism" may be a more common feature of homothallic species, than thus far anticipated. The total rate of outcrossing in this situation, however, might be significantly less than previously described [174], as more recent investigations suggest $[178,179]$.

The signal transduction pathways downstream of sexpheromone GPCR activation, including G-proteins, Ras GTPase, MAPK cascades and associated transcription factors, are as conserved in A. nidulans, as in other filamentous species, and have recently been summarized [180]. This confirms that once the (functional) heterodikaryon has been assembled subsequent processes required for the production of sexual spores follow common themes, obviously, including species-specific morphogenetic adaptations.

Overall, the comparison of these different mating systems poses the question whether homothallism is "functional heterothallism" generated by differential gene expression on the transcriptional level during selfing and outcrossing in obligate and facultative homothallic species, whereas, obligate heterothallic species create this functional distinction between nuclei on the genetic level of the whole organism. If true, the diversity of individually defined mating systems would significantly decrease, because ultimately most could be defined as heterothallism, simply achieved by different combinations of morphology and genetics.

The recent breakthrough discoveries of sexual reproduction in previously "asexual" aspergilli, including 
A. fumigatus [181], A. parasiticus [182], A. flavus [183] and A. nomius [184], opened up new avenues for a direct comparison of homothallic, "functional heterothallic", pseudohomothallic, heterothallic and "relative heterothallic" breeding systems within the same genus, and as such may help to answer this question.

For further reading about fungal mating systems, matingtype genetics, vegetative heterokaryon incompatibility, and the influence of different mating systems on fungal evolution, we refer the reader to comprehensive recent reviews $[23,152,171,185]$.

\section{CHEMOATTRACTION FOR FORAGING}

The filamentous fungal lifestyle is believed to have evolved as an adaptation to facilitate foraging for nutrients despite the general lack of motility of the organism [186]. Chemotropic growth of an individual hypha towards a vegetative- or sexual-fusion partner, guided by self-signaling molecules or sex pheromones, has been discussed in detail already. Chemotropic growth towards nutrients can be considered to follow the same basic rules, except that it involves whole colony sectors. The likely scenario is that as soon as an exploratory hypha encounters a new carbon and/or nitrogen source, this information will be relayed through the vegetative network and result in the promotion of directed growth of more hyphae from this sector towards the nutrient source. Fungi are generally enabled by the mycelium to develop gigantic colony networks, as in the extreme example of Armilaria bulbosa, which can occupy up to $150,000 \mathrm{~m}^{2}$ [187]. In order to allow rapid extension and to outgrow potential competitors, promoted growth towards a new nutrient source might also involve withdrawal and recycling of cytoplasmic content from older colony sectors in already nutrient depleted regions. Over longer time periods, this shifting of the "living part" of the colony can result in linear relocation of the whole organism. This behavior is observed when wood block inocula are presented to mycelia [188]. The practically indefinite expansion and adaptation of the mycelial network, thus, confers significant advantages over the root systems of the more sessile plants. Are filamentous fungi attracted towards nutrients; is nutrient foraging the result of chance encounters or are hyphae attracted along gradients of volatile chemicals? Some interactions involving volatiles have been studied (see below) and strategies for surviving environments with no nutrients have been observed, for example during preinfection of the rice blast fungus $M$. oryzae [189]. Whether these strategies involve chemoattraction or not is currently unclear.

Inter- and intraspecies interactions through volatile organic compounds. In their natural environment, fungi interact with other fungi, with bacteria, plants and animals [190-192]. Interspecific fungal interactions may be mediated upon contact, or even at a distance, and include antagonism and mycoparasitism to defend the living space of the individual. Antagonism describes the interference or the inhibition of the growth of a competing organism often at a distance [188]. In this context, usually referring to another fungal species, or a "non-self", and is most likely facilitated by volatile compounds. Mycoparasitism is a foraging strategy, which allows the attacking fungus to use its prey fungus as nutrient source. In soil, a mycelium will encounter and interact with mycelia of the same fungus and with that of different fungal species. Nonself recognition usually results in antagonistic responses, morphological changes, and/or production of extracellular enzymes, volatile and diffusible secondary metabolites [188].

Interactions of filamentous fungi with other fungi or other organisms that occur prior to physical contact are likely to be induced by volatile organic compounds, known as VOCs [193, 194]. VOC-mediated positive, negative and neutral interactions occur between a wide range of fungi and other organisms, often species-specific and influencing processes in the wider biosphere [195, 196]. Approximately 250 VOCs have already been identified and characterized in fungi, varying in function from antifungal to attractant [197]. Several authors have recently reviewed various aspects of fungal VOCs, specifically, indirectly, or in tandem with VOCs produced by other organisms [190, 196-199].

In the soil environment, hydrolytic activity of extracellular fungal enzymes is important in nutritional sourcing and for the constant competition between fungi and bacteria. Bactericidal effects of fungi have most likely coevolved with other strategies such as the acidification of the microenvironment by oxalic acid [190]. Contemporary knowledge of fungal VOCs has been collated in a recent review discussing the important signaling roles of VOCs in the natural environment, their detection, toxicity and the potential biotechnological applications for fungal VOCs [197]. The roles of many fungal VOCs as infochemicals (information conveying chemicals; [200]) or semiochemicals (naturally produced signaling chemicals; [201]) have been elucidated, and due to their ability to affect organisms within and between species, as well as across kingdoms, they have been exploited for biocontrol in agriculture [197]. Semiochemicals identified from fungi include volatiles that range from simple hydrocarbons to complex heterocyclic compounds, aldehydes and alcohols to ketones [196, 197]. The mycoparasitic Trichoderma spp., mentioned earlier, have been highlighted for their effectiveness at enzymatically degrading other fungi [197]. Species of Trichoderma are known to produce many VOCs and their secondary metabolites have targeted antimicrobial effects on other fungal species at very low concentrations irrespective of the culture substrate [202].

Many VOCs facilitate interactions between plant roots and soil organisms, including fungal-fungal interactions. Fungistasis may also result from the presence of fungal volatiles, whereby VOCs, for example, block germination or protein synthesis [198]. Some VOCs produced by microorganisms have potential for the control of plant pathogens; this area of research, however, is in its infancy [199].

Mycoparasitism in fungi, which involves fungus-fungus crosstalk between the host and parasite, has mainly been studied in the ascomycete Trichoderma atroviride, however other associations have also been investigated, such as between Stachybotris elegans and Rhizoctonia solani. A role 
for MAP kinases in mycoparasitism has also been indicated [203, 204]. Changes in MAPK/ERK1/2 expression was observed in $S$. elegans in response to the stress of both direct mycoparasitism and poor nutritional conditions [203]. In species-specific interactions, the manipulation of amino acid levels, while maintaining stable $\mathrm{C}: \mathrm{N}$ ratios, resulted in reproducible changes of VOC output from Trichoderma isolates by inhibiting growth of target filamentous fungi [196]. A comprehensive overview on filamentous fungal mycoparasitism has been provided by other authors in this special issue of The Open Mycology Journal.

\section{CHEMOATTRACTION DURING PLANT PATHO- GENESIS AND SYMBIOSIS}

Strategies for nutrient acquisition during fungal infection of plants involves elaborate mechanisms where host and pathogen compete for nutrient supplies; fungi can exploit plant defense mechanisms for nutritional purposes [205]. Evidence of amino acids, including the nonprotein amino acids GABA and ornithine, as potential nitrogen sources for the pathogenic fungus has been presented. Although, we know little of the molecular basis of how fungi entrain host metabolism [205].

A common theme of fungus-host interaction is how the fungus exploits an often chance encounter with its host. Fungi radiate out, either by a mycelial network or by producing an abundance of spores, to increase the chance of meeting a susceptible host. However, what is not clear is the significance of chemoattraction during this interaction.

While many filamentous fungi thrive as plant pathogens, other fungi live in symbiotic relationships with plants. The idea that colonization of land by plants over 400mya was facilitated by symbiotic fungi, presumably to enhance nutrient uptake, has been gaining acceptance [206]. Today, the arbuscular mycorrhizal (AM) fungi (Glomeromycotina) are the most common type of fungus forming mutualistic intracellular associations with the roots of vascular plants. However, other symbiotic associations have existed and still do, including those between lower plants and other lineages of fungi, for example between liverworts and Mucoromycotina [206]. The signaling and cellular programs of the arbuscular mycorrhizal fungi have been extensively reviewed elsewhere [207, 208]. In summary, AM fungi perceive diffusible signals before any physical interaction occurs with their plant symbiont [207]. Root colonization is vital to AM fungi and compounds released by the plant that stimulate AM fungal metabolism have been identified as strigolactones, these compounds have multiple functions and could be considered hormones [208]. The cellular programs and common themes for ectomycorrhizal (EM) and AM symbioses are beginning to emerge, but only a handful of proteins have been identified, and their precise roles remain unclear [208, 209]. Once in contact with the plant, an AM fungus receives appressoria-inducing signals that show similarities with those received by pathogenic fungi. Also, once within the plant, significant developmental changes happen to the fungus, but again, the nature of the inducing signals is unknown [207]. Data from the EM fungus
Laccaria bicolor also point to similarities with the mechanisms of effector-like proteins, as seen in pathogenic fungi. However, comparable effector-like proteins have not been observed in Tuber melanosporum, another EM fungus [208].

Plants have evolved immune systems that can recognize potential pathogens and trigger chemical defence responses. In return, successful fungal plant pathogens secrete proteins, known as effectors or virulence factors. Fungal effectors are recognized by plant-resistance-proteins, which due to their importance for crop plant protection, have been the subject of many excellent reviews (including: [210-212]). The use of comparative genomics and fluorescence microscopy has been envisaged as a way to identify interactions of fungal effector proteins [211]. Whether interactions between fungal effector proteins play a role in chemoattraction of filamentous fungi is not clear, as most of the literature concentrates on the host-pathogen interaction rather than the fungus-fungus interaction. However, by understanding hostpathogen interactions, this may supply clues to potential chemoattractive mechanisms between fungi. In 2011, Dodds and Rathjen reviewed the molecular basis of plant-pathogen interactions, concluding that the area was extremely underexplored and that our knowledge of host-pathogen coevolution was "poorly developed" [213]. If chemo attraction is not involved in these interactions then it is probable that other tropisms are involved, for example, thigmotropism [214].

A recently researched example of a host-pathogen interaction is that of powdery mildew of barley, Blumeria graminis f. sp. hordei [215]. Results indicated that either the host activated a generic mechanism to reduce the transcription of small, secreted proteins or that the fungus was able to sense unsuccessful invasion and consequently shut down the transcription of a particular set of candidatesecreted effector proteins. Comparative genomics have suggested that the organization of effector genes drives effector evolution in many pathogen genomes [216]. In silico analyses have also been used to identify putative effectors, including candidates in the secretome of the ubiquitous plant-associated fungus Piriformospora indica [212, 217]. Some authors have reviewed unifying themes of fungal interactions with both plant and animal hosts [218, 219]. Few universal virulence factors within and between animal and plant pathogens have been identified, but insufficient indepth studies have been made. Common signaling cascades and protective compounds appear to be utilized by many pathogens during their pathogenic development. For example, oxylipins have been highlighted as playing an important signaling role in disease [218] and MAP kinase activation has been proposed as an effective target for effectors in both plant and animal host systems [219].

Another point to note is the role of oxidative stress. There is increasing evidence for the importance of ROS in many aspects of the fungal lifestyle, from hyphal growth to cell differentiation, infection structure formation to induction of apoptosis [220]. Fungi combat ROS that are produced by the host-plant tissue in response to fungal attack, with complex oxidative stress responses. The relationship of oxidative stress with secondary metabolism in fungi is the subject of 
another very recent review [221]. In this review the authors summarized the infection process in a series of steps, where the fungal pathogen initially overcomes the host (plant) defensive oxidative burst by activating expression of detoxifying antioxidants. The oxidative burst can trigger secondary metabolite biosynthesis that can act as a scavenging mechanism against ROS, thus enabling survival of the fungus. It seems unlikely that chemoattraction is involved here, and little information is available on how oxidants and antioxidants are poised to provide regulation between oxidative stress, secondary metabolism and cell development.

A successful strategy employed by some pathogenic microorganisms is that of quorum sensing (QS), an important mechanism of communication using hormone-like molecules. In contrast to bacteriological QS research, fungal QS research is in its infancy and has recently been reviewed [222]. QS research with Candida albicans and other fungi has suggested that cell density and QS molecules play a role in virulence, but the signaling pathways involved are yet to be understood. So far, the most researched fungal QS molecule is farnesol, which appears to have multiple roles during infection [222, 223]. A comprehensive review of selfsignaling molecules employed by ascomycetes and the quest to understand their biological function, including chemoattraction, has also recently been provided [61].

In summary, a considerable number of diverse chemoattraction systems employed by filamentous fungi in the context of nutrient identification and exploitation, as well as for symbiosis and pathogenesis are known. However, the underlying molecular mechanisms remain poorly understood. Especially in the area of fungal plant pathogenesis and mycoparasitism, focus has so far been on responses elicited by the host plant or prey fungus and to a much lesser extent on the recognition system of the attacking fungus. Cleary, more research needs to be directed towards a better understanding of how fungi identify, localize and establish physical interactions with their host. Being able to block these initial steps promises powerful tools for disease prevention.

\section{CONCLUDING REMARKS}

Chemoattractive mechanisms are essential for fungal life and are employed in a broad range of biological functions. This functional diversity is clearly reflected by the considerable variety of molecular mechanisms underlying positive chemotropic responses, and the complex integration of individual proteins in different pathways. In recent years the number of identified fusion proteins has impressively increased and enabled the community to build signaling pathway networks and assign specific functional roles to those fusion proteins. The greatest challenge, however, still is to identify the signaling proteins that are exchanged through the intercellular space, and how they are perceived by the respective interaction partner.

\section{CONFLICT OF INTEREST}

The authors confirm that this article content has no conflict of interest.

\section{ACKNOWLEDGEMENTS}

We wish to thank Dr. Paul Dyer (University of Nottingham, UK), Dr. Fabienne Malagnac (Université Paris Diderot, FR), Dr. Stephan Seiler (University of Freiburg, DE) and Dr. Ines Teichert (Ruhr-University Bochum, DE) for helpful discussion during the preparation of this manuscript. We furthermore, wish to apologize to all colleagues whose work did not find appropriate recognition in this article, or whose articles we may have inadvertently missed.

\section{REFERENCES}

[1] Machlis L. A procedure for the purification of sirenin. Nature 1958; 181: 1790-1.

[2] Pommerville J, Olson LW. Evidence for a male-produced pheromone in Allomyces Macrogynus. Exp Mycol 1987; 11(3): 245-8.

[3] Pommerville J. Analysis of gamete and zygote motility in Allomyces. Expe Cell Res 1978; 113(1): 161-72.

[4] Wubah DA, Kim DS. Chemoattraction of anaerobic ruminal fungi zoospores to selected phenolic acids. Microbiol Res 1996; 151(3): 257-62.

[5] Deacon JW, Donaldson SP. Molecular recognition in the homing responses of zoosporic fungi, with special reference to Pythium and Phytophthora. Mycol Res 1993; 97(10): 1153-71.

[6] Morris PF, Ward EWB. Chemoattraction of zoospores of the soybean pathogen, phytophthora sojae, by isoflavones. Physiol Mol Plant Pathol 1992; 40(1): 17-22.

[7] Hua C, Wang Y, Zheng X, et al. A Phytophthora Sojae G-protein alpha subunit is involved in chemotaxis to soybean isoflavones. Eukaryot Cell 2008; 7(12): 2133-40.

[8] Hua C, Zheng X, Wang Y. G Protein alpha subunit may help zoospore to find the infection site and influence the expression of Rgs protein. Commun Integr Biol 2009; 2(2): 91-3.

[9] Wang Y, Li A, Wang X, et al. Gpr11, a putative seventransmembrane $\mathrm{G}$ protein-coupled receptor, controls zoospore development and virulence of Phytophthora Sojae. Eukaryot Cell, 2010; 9(2): 242-50.

[10] Muehlstein LK, Amon JP, Leffler DL. Chemotaxis in the marine fungus Rhizophydium Littoreum. Appl Environ Microbiol 1988; 54(7): 1668-72.

[11] Moss AS, Reddy NS, Dortaj IM, San Francisco MJ. Chemotaxis of the amphibian pathogen Batrachochytrium Dendrobatidis and its response to a variety of attractants. Mycologia 2008; 100(1): 1-5.

[12] Kilpatrick AM, Briggs CJ, Daszak P. The ecology and impact of chytridiomycosis: an emerging disease of amphibians. Trends Ecol Evol 2010; 25(2): 109-18.

[13] El-Feki M, Hatai K, Hussein MMA. Chemotactic and chemokinetic activities of Saprolegnia Parasitica toward different metabolites and fish tissue extracts. Mycoscience 2003; 44(2): 0159-62.

[14] Islam MT, Tahara S. Chemotaxis of fungal zoospores, with special reference to Aphanomyces Cochlioides. Biosci Biotechnol Biochem 2001; 65(9): 1933-48.

[15] Gow NAR. New angles in mycology: studies in directional growth and directional motility. Mycol Res 2004; 108(1): 5-13.

[16] Reid B, Morris BM, Gow NAR. Calcium-dependent, genusspecific, autoaggregation of zoospores of phytopathogenic fungi. Exp Mycol 1995; 19(3): 202-213.

[17] Lee SC, Ristaino JB, Heitman J. Parallels in intercellular communication in oomycete and fungal pathogens of plants and humans. PLoS Pathog 2012; 8(12): e1003028.

[18] Qi J, Asano T, Jinno M, et al. Characterization of a Phytophthora mating hormone. Science 2005; 309(5742): 1828.

[19] Yajima A, Qin Y, Zhou X, et al. Synthesis and absolute configuration of hormone alpha1. Nat Chem Biol 2008; 4(4): 2357.

[20] Ojika M, Molli SD, Kanazawa H, et al. The second Phytophthora mating hormone defines interspecies biosynthetic crosstalk. Nat Chem Biol 2011; 7(9): 591-3.

[21] Judelson HS, Blanco FA. The spores of Phytophthora: weapons of the plant destroyer. Nat Rev Microbiol 2005; 3(1): 47-58. 
[22] Ko W-H. Hormonal regulation of sexual reproduction in Phytophthora. Bot Stud 2007; 48(4): 365-75.

[23] Aanen DK, Debetes AJM, Glass NL, Saupe SJ. Biology and genetics of vegetative incompatibility in fungi, In: Borkovich KA, Ebole D, Eds. Cellular and molecular biology of filamentous fungi. American Society for Microbiology Press: Washington, DC. 2010; 274-88.

[24] Perkins DD. Main features of vegetative incompatibility in Neurospora Crassa. Fungal Genet Newsl 1988; 35: 44-6.

[25] Glass NL, Dementhon K. Non-self recognition and programmed cell death in filamentous fungi. Curr Opin Microbiol 2006; 9(6): 553-8

[26] Sarkar S, Iyer G, Wu J, Glass NL. Nonself recognition is mediated by het-c heterocomplex formation during vegetative incompatibility. EMBO J 2002; 21(18): 4841-50.

[27] Kaneko I, Dementhon K, Xiang Q, Glass NL. Nonallelic interactions between het-c and a polymorphic locus, pin-c, are essential for nonself recognition and programmed cell death in Neurospora Crassa. Genetics 2006; 172(3): 1545-55.

[28] Dementhon K, Iyer G, Glass NL. Vib-1 is required for expression of genes necessary for programmed cell death in Neurospora Crassa. Eukaryot Cell 2006; 5(12): 2161-73.

[29] Hall C, Welch J, Kowbel DJ, Glass NL. Evolution and diversity of a fungal self/nonself recognition locus. PLoS One 2010; 5(11): e14055.

[30] Hutchison EA, Bueche JA, Glass NL. Diversification of a protein kinase cascade: Ime-2 is involved in nonself recognition and programmed cell death in Neurospora Crassa. Genetics 2012; 192(2): 467-82.

[31] Ishikawa FH, Souza EA, Shoji J-y, et al. Heterokaryon incompatibility is suppressed following conidial anastomosis tube fusion in a fungal plant pathogen. PLoS ONE 2012; 7(2): e31175.

[32] Wilson JF, Dempsey JA. A hyphal fusion mutant in Neurospora Crassa. Fungal Genet Newsl 1999; 46: 31.

[33] Fleißner A, Glass NL. So, a protein involved in hyphal fusion in neurospora crassa, localizes to septal plugs. Eukaryot Cell 2007; 6(1): 84-94.

[34] Fleißner A, Leeder AC, Roca MG, Read ND, Glass NL. Oscillatory recruitment of signaling proteins to cell tips promotes coordinated behaviour during cell fusion. Proc Natil Academy Sci USA 2009; 106(46): 19387-92.

[35] Fleißner A, Sarkar S, Jacobson DJ, et al. The So locus is required for vegetative cell fusion and postfertilization events in Neurospora Crassa. Eukaryot Cell 2005; 4(5): 920-30.

[36] Xiang Q, Rasmussen C, Glass NL. The Ham-2 locus, encoding a putative transmembrane protein, is required for hyphal fusion in Neurospora Crassa. Genetics 2002; 160: 169-80.

[37] Roca GM, Arlt J, Jeffree CE, Read ND. Cell biology of conidial anastomosis tubes in Neurospora Crassa. Eukaryot Cell 2005; 4(5): $911-9$.

[38] Hickey PC, Jacobson DJ, Read ND, Glass LN. Live-cell imaging of vegetative hyphal fusion in Neurospora Crassa. Fungal Genet Biol 2002; 37(1): 109-19.

[39] Dettmann A, Heilig Y, Ludwig S, et al. Ham-2 and Ham-3 are central for the assembly of the Neurospora stripak complex at the nuclear envelope and regulate nuclear accumulation of the map kinase Mak-1 in a Mak-2-dependent manner. Mol Microbiol 2013; 90(4): 796-812.

[40] Li D, Bobrowicz P, Wilkinson HH, Ebbole DJ. A mitogenactivated protein kinase pathway essential for mating and contributing to vegetative growth in Neurospora Crassa. Genetics 2005; 170: 1091-104

[41] Pandey A, Roca GM, Read ND, Glass NL. Role of a mitogenactivated protein kinase pathway during conidial germination and hyphal fusion in Neurospora Crassa. Eukaryot Cell 2004; 3(2): 348-58.

[42] Kothe GO, Free SJ. The isolation and characterization of $n r c-1$ and $n r c-2$, two genes encoding protein kinases that control growth and development in Neurospora Crassa. Genetics, 1998; 149(1): 117130.

[43] Galagan JE, Calvo SE, Borkovich KA, et al. The genome sequence of the filamentous fungus Neurospora Crassa. Nature 2003; 422(6934): 859-68.

[44] Colot HV, Park G, Turner GE, et al. A high-throughput gene knockout procedure for Neurospora reveals functions for multiple transcription factors. Proc Natl Acad Sci USA 2006; 103(27): 10352-7.

[45] Dunlap JC, Borkovich KA, Henn MR, et al. Enabling a community to dissect an organism: overview of the Neurospora functional genomics project. In: Dunlap JC, Ed. Fungal Genomics. Academic Press. 2007; 49-96

[46] Kays AM, Borkovich KA. Severe impairment of growth and differentiation in a Neurospora Crassa mutant lacking all heterotrimeric g-alpha proteins. Genetics 2004; 166(3): 1229-40.

[47] Kim H, Borkovich KA. A pheromone receptor gene, Pre-1, is essential for mating type-specific directional growth and fusion of trichogynes and female fertility in Neurospora Crassa. Mol Microbiol 2004; 52(6): 1781-98.

[48] Kim H, Borkovich KA. Pheromones are essential for male fertility and sufficient to direct chemotropic polarized growth of trichogynes during mating in Neurospora Crassa. Eukaryot Cell 2006; 5(3): 544-54.

[49] Coppin E, de Renty C, Debuchy R. The function of the coding sequences for the putative pheromone precursors in Podospora Anserina is restricted to fertilization. Eukaryot Cell 2005; 4(2): 407-20.

[50] Seo JA, Han KH, Yu JH. The Gpra and Gprb genes encode putative $\mathrm{G}$ protein-coupled receptors required for self-fertilization in Aspergillus Nidulans. Mol Microbiol 2004; 53(6): 1611-23.

[51] Mayrhofer S, Pöggeler S. Functional characterization of an alphafactor-like Sordaria Macrospora Peptide pheromone and analysis of its interaction with its cognate receptor in Saccharomyces Cerevisiae. Eukaryot Cell 2005; 4(4): 661-72.

[52] Roca GM, Read ND, Wheals AE. Conidial Anastomosis tubes in filamentous fungi. FEMS Microbiological Letters 2005; 249: 1918 .

[53] Araujo-Palomares CL, Castro-Longoria E, Riquelme M. Ontogeny of the spitzenkörper in germlings of Neurospora Crassa. Fungal Genet Biol 2007; 44(6): 492-503.

[54] Riquelme M, Reynaga-Pena CG, Gierz G, Bartnicki-Garcia S. What Determines Growth Direction in Fungal Hyphae? Fungal Genet Biol 1998; 24: 101-9.

[55] Riquelme M, Yarden O, Bartnicki-Garcia S, et al. Architecture and development of the Neurospora Crassa Hypha -- a model cell for polarized growth. Fungal Biol 2011; 115(6): 446-74.

[56] Verdín J, Bartnicki-Garcia S, Riquelme M. Functional stratification of the spitzenkörper of Neurospora Crassa. Mol Microbiol 2009; 74(5): 1044-53.

[57] Lichius A, Berepiki A, Read ND. Form follows function: the versatile fungal cytoskeleton. Fungal Biol 2011; 115: 518-40.

[58] Berepiki A, Lichius A, Read ND. Actin organization and dynamics in filamentous fungi. Nat Rev Microbiol 2011; 9(12): 876-87.

[59] Lichius A, Goryachev AB, Fricker MD, et al. Cdc-42 and Rac-1 Regulate opposite chemotropisms in Neurospora Crassa. J Cell Sci 2014; 127(9): 1953-66.

[60] Read ND, Lichius A, Shoji J, Goryachev AB. Self-Signalling and self-fusion in filamentous fungi. Curr Opin Microbiol 2009; 12: 608-15.

[61] Leeder AC, Palma-Guerrero J, Glass NL. The social network: deciphering fungal language. Nat Rev Microbiol 2011; 9(6): 44051.

[62] Fleißner A, Simonin AR, Glass NL. Cell Fusion in the filamentous fungus Neurospora Crassa. Method Mole Biol 2008; 475: 21-38.

[63] Read ND, Fleißner A, Roca MG, Glass NL. Hyphal Fusion. In: Borkovich KA, Ebbole D, Eds. Cellular and molecular biology of filamentous fungi. American Society of Microbiology: Washington DC. 2010.

[64] Read ND, Goryachev AB, Lichius A. The mechanistic basis of self-fusion between conidial anastomosis tubes during fungal colony initiation. Fungal Biol Rev 2012; 26: 1-11.

[65] Fleissner A. Hyphal fusion. In: Perez-Martin J, Di Pietro A, Eds. Morphogenesis and pathogenicity in fungi. Springer: Heidelberg. 2012; 43-60.

[66] Leeder AC, Jonkers W, Li J, Glass NL. Early colony establishment in neurospora crassa requires a map kinase regulatory network. Genetics 2013; 195(3): 883-98.

[67] Fu C, Iyer P, Herkal A, et al. Identification and characterization of genes required for cell-to-cell fusion in Neurospora Crassa. Eukaryot Cell 2011; 10(8): 1100-9. 
[68] McCluskey K, Plamann M. The Fungal genetics stock center: a repository for 50 years of fungal genetics research. J Biosci 2010; 35: 119-26.

[69] Goryachev AB, Lichius A, Wright GD, Read ND. Excitable behavior can explain the "ping-pong" mode of communication between cells using the same chemoattractant. Bioessays 2012; 34(4): 259-66.

[70] Dettmann A, Illgen J, März S, et al. The Ndr kinase scaffold Hym1/Mo25 is essential for mak2 map kinase signaling in Neurospora Crassa. PLoS Genetics, 2012; 8(9): e1002950.

[71] Simonin AR, Rasmussen CG, Yang M, Glass NL. Genes encoding a striatin-like protein (Ham-3) and a forkhead associated protein (Ham-4) are required for hyphal fusion in Neurospora Crassa. Fungal Genet Biol 2010; 47(10): 855-68.

[72] Schuerg T, Brandt U, Adis C, Fleissner A. The Saccharomyces Cerevisiae bem 1 homologue in Neurospora Crassa promotes coordinated cell behaviour resulting in cell fusion. Mol Microbiol 2012; 86(2): 349-66.

[73] Lichius A. Cell fusion in Neurospora Crassa, in Institute of Cellular and Molecular Biology. The University of Edinburgh: Edinburgh (UK). 2010; 401

[74] Maddi A, Dettman A, Fu C, Seiler S, Free SJ. Wsc-1 and Ham-7 are Mak-1 map kinase pathway sensors required for cell wall integrity and hyphal fusion in Neurospora Crassa. PLoS One 2012; 7(8): e42374.

[75] Richthammer C, Enseleit M, Sanchez-Leon E, et al. Rho1 and rho2 share partially overlapping functions in the regulation of cell wall integrity and hyphal polarity in Neurospora Crassa. Mol Microbiol 2012; 85(4): 716-33.

[76] Lichius A, Lord KM, Jeffree CE, et al. Importance of map kinases during protoperithecial morphogenesis in Neurospora Crassa. PLoS One, 2012; 7(8): 1-21.

[77] Maerz S, Ziv C, Vogt N, et al. The nuclear dbf2-related kinase cot1 and the mitogen-activated protein kinases mak1 and mak2 genetically interact to regulate filamentous growth, hyphal fusion and sexual development in Neurospora Crassa. Genetics 2008; 179(3): 1313-25.

[78] Mähs A, Ischebeck T, Heilig $\mathrm{Y}$, et al. The essential phosphoinositide kinase mss-4 is required for polar hyphal morphogenesis, localizing to sites of growth and cell fusion in Neurospora Crassa. PLoS One 2012; 7(12): e51454.

[79] Lichius A, Yanez-Gutierrez ME, Read ND, Castro-Longoria E. Comparative live-cell imaging analyses of spa-2, bud- 6 and bni-1 in Neurospora Crassa reveal novel features of the filamentous fungal polarisome. PLoS One 2012; 7(1): e30372.

[80] Maerz S, Dettmann A, Ziv C, et al. Two ndr kinase-mob complexes function as distinct modules during septum formation and tip extension in Neurospora Crassa. Mol Microbiol 2009; 74(3): 707-23.

[81] Bernhards Y, Pöggeler S. The Phocein homologue smmob3 is essential for vegetative cell fusion and sexual development in the filamentous ascomycete Sordaria Macrospora. Curr Genet 2011; 57(2): 133-49.

[82] Berepiki A, Read ND. Septins are important for cell polarity, septation and asexual spore formation in Neurospora Crassa and show different patterns of localisation at germ tube tips. PLoS One, 2013; 8(5): e63843.

[83] Roca MG, Kuo H-C, Lichius A, Freitag M, Read ND. Nuclear Dynamics, mitosis and the cytoskeleton during the early stages of colony initiation in Neurospora Crassa. Eukaryot Cell 2010; 9(8): 1171-1183.

[84] Berepiki A, Lichius A, Shoji J, Tilsner J, Read ND. F-actin dynamics in Neurospora Crassa. Eukaryot Cell 2010; 9(4): 547-7.

[85] Lichius A, Roca MG, Read ND. How to distinguish conidial anastomosis tubes (cats) from germ tubes. The Neurospora protocol guide 2010: 1-6.

[86] Takemoto D, Tanaka A, Scott B. A P67phox-like regulator is recruited to control hyphal branching in a fungal-grass mutualistic symbiosis. Plant Cell 2006; 18(10): 2807-21.

[87] Tanaka A, Christensen MJ, Takemoto D, Park P, Scott B. Reactive oxygen species play a role in regulating a fungus-perennial ryegrass mutualistic interaction. Plant Cell 2006; 18(4): 1052-66.

[88] Takemoto D, Kamakura S, Saikia S, et al. Polarity proteins bem1 and $\operatorname{cdc} 24$ are components of the filamentous fungal nadph oxidase complex. Proc Natl Acad Sci USA 2011; 108(7): 2861-6.
[89] Tanaka A, Cartwright GM, Saikia S, et al. Proa, a transcriptional regulator of fungal fruiting body development, regulates leaf hyphal network development in the Epichloe Festucae-Lolium Perenne symbiosis. Mol Microbiol 2013; 90(3): 551-68.

[90] Caño-Domínguez N, Álvarez-Delfín K, Hansberg W, Aguirre J. Nadph oxidases nox-1 and nox-2 require the regulatory subunit nor-1 to control cell differentiation and growth in Neurospora Crassa. Eukaryot Cell 2008; 7(8): 1352-61.

[91] Roca MG, Weichert M, Siegmund U, Tudzynski P, Fleissner A. Germling Fusion Via Conidial Anastomosis Tubes in the Grey Mould Botrytis Cinerea Requires Nadph Oxidase Activity. Fungal Biol 2012; 116(3): 379-87.

[92] Kayano Y, Tanaka A, Akano F, Scott B, Takemoto D. Differential roles of nadph oxidases and associated regulators in polarized growth, conidiation and hyphal fusion in the symbiotic fungus epichloe festucae. Fungal Genet Biol 2013; 56: 87-97.

[93] Palma-Guerrero J, Hall CR, Kowbel D, et al. Genome wide association identifies novel loci involved in fungal communication. PLoS Genet 2013; 9(8): e1003669.

[94] Palma-Guerrero J, Huang IC, Jansson HB, et al. Chitosan permeabilizes the plasma membrane and kills cells of Neurospora Crassa in an energy dependent manner. Fungal Genet Biol 2009; 46(8): 585-94.

[95] Fischer-Harman V, Jackson KJ, Muñoz A, Shoji JY, Read ND. Evidence for tryptophan being a signal molecule that inhibits conidial anastomosis tube fusion during colony initiation in Neurospora Crassa. Fungal Genet Biol 2012; 49(11): 896-902.

[96] Fleißner A, Diamond S, Glass NL. The Saccharomyces Cerevisiae prm1 homolog in Neurospora Crassa is involved in vegetative and sexual cell fusion events but also has postfertilization functions. Genetics 2009; 181(2): 497-510.

[97] Aldabbous MS, Roca MG, Stout A, et al. The Ham-5, Rcm-1 and Rco-1 genes regulate hyphal fusion in neurospora crassa. Microbiology 2010; 156(Pt 9): 2621-9.

[98] Simonin A, Palma-Guerrero J, Fricker M, Glass NL. Physiological significance of network organization in fungi. Eukaryot Cell 2012; 11(11): 1345-52.

[99] Richard F, Glass NL, Pringle A. Cooperation among germinating spores facilitates the growth of the fungus, Neurospora Crassa. Biol Lett 2012; 8(3): 419-22.

[100] Prados Rosales RC, Di Pietro A. Vegetative Hyphal Fusion Is Not Essential for Plant Infection by Fusarium Oxysporum. Eukaryot Cell 2008; 7(1): 162-71.

[101] Rispail N, Di Pietro A. Fusarium Oxysporum Ste12 controls invasive growth and virulence downstream of the fmk1 mapk cascade. Mol Plant Microbe Interact 2009; 22(7): 830-9.

[102] Ruiz-Roldan MC, Kohli M, Roncero MI, et al. Nuclear dynamics during germination, conidiation, and hyphal fusion of Fusarium Oxysporum. Eukaryot Cell 2010; 9(8): 1216-24.

[103] Roca MG, Davide LC, Davide LMC, et al. Conidial anastomosis fusion between Colletotrichum species. Mycol Res 2004; 108(11): 1320-6.

[104] Veneault-Fourrey C, Barooah M, Egan M, Wakley G, Talbot NJ. Autophagic fungal cell death is necessary for infection by the rice blast fungus. Science 2006; 312(5773): 580-3.

[105] Lopez-Berges MS, Rispail N, Prados-Rosales RC, Di Pietro A. A nitrogen response pathway regulates virulence functions in Fusarium Oxysporum via the protein kinase tor and the bzip protein meab. Plant Cell 2010; 22(7): 2459-75.

[106] Hou Z, Xue C, Peng Y, et al. A mitogen-activated protein kinase gene (mgv1) in Fusarium Graminearum is required for female fertility, heterokaryon formation, and plant infection. Mol Plant Microbe In 2002; 15(11): 1119-27.

[107] Roca MG, Davide LC, Mendes-Costa MC, Wheals A. Conidial anastomosis tubes in Colletotrichum. Fungal Genet Biol 2003; 40(2): 138-45.

[108] Ishikawa FH, Souza EA, Read ND, Roca MG. Live-cell imaging of conidial fusion in the bean pathogen, Colletotrichum Lindemuthianum. Fungal Biol 2010; 114(1): 2-9.

[109] Craven KD, Velez H, Cho Y, Lawrence CB, Mitchell TK. Anastomosis is required for virulence of the fungal necrotroph Alternaria Brassicicola. Eukaryot Cell 2008; 7(4): 675-83.

[110] Cho Y, Cramer RA, Jr., Kim KH, et al. The fus3/kss1 map kinase homolog amk1 regulates the expression of genes encoding hydrolytic enzymes in Alternaria Brassicicola. Fungal Genet Biol 2007; 44(6): 543-53. 
[111] Sbrana C, Fortuna P, Giovannetti M. Plugging into the network: belowground connections between germlings and extraradical mycelium of arbuscular mycorrhizal fungi. Mycologia 2011; 103(2): 307-16.

[112] Westergaard M, Mitchell HK. Neurospora. V. A Synthetic medium favouring sexual reproduction. Am J Bot 1947; 34: 573-7.

[113] Backus MP. The mechanics of conidial fertilization in Neurospora Sitophila. Bull Torrey Bot Club 1939; 1939(66): 63-76.

[114] Bistis GN. Chemotropic interactions between trichogynes and conidia of opposite mating-type in Neurospora Crassa. Mycologia 1981; 73: 959-75.

[115] Kim H, Wright SJ, Park G, et al. Roles for receptors, pheromones, $\mathrm{g}$ proteins, and mating type genes during sexual reproduction in Neurospora Crassa. Genetics 2012; 190(4): 1389-404.

[116] Kim DJ, Schacht PC, Garud AV, Park G, Borkovich KA. Heterodimeric G Proteins. In: Kasbekar DP, McCluskey K, Eds. Neurospora: Genomics and Molecular Biology. Caister Academic Press. 2013; 193-207.

[117] Raju NB. Meiosis and ascospore genesis in Neurospora. Eur J Cell Biol 1980; 23: 208-23.

[118] Raju NB. Genetic control of the sexual cycle in Neurospora. Mycol Res 1992; 96: 241-262.

[119] Raju NB. Six decades of Neurospora ascus biology at Stanford. Fungal Biol Rev 2008; 22(1): 26-35.

[120] Raju NB. Neurospora as a model fungus for studies in cytogenetics and sexual biology at Stanford. J Biosci 2009; 34(1): 139-59.

[121] Johnson TE. A Neurospora mutation that arrests perithecial development as either male or female parent. Genetics 1979; 92(4): 1107-20.

[122] Iyer SV, Ramakrishnan M, Kasbekar DP. Neurospora Crassa Fmf1 Encodes the homologue of the Schizosaccharomyces pombe ste11p regulator of sexual development. J Genet 2009; 88(1): 33-9.

[123] Beadle GW, Coonradt VL. Heterocaryosis in Neurospora Crassa. Genetics 1944; 29(3): 291-308.

[124] Glass NL, Vollmer SJ, Staben C, et al. Dnas of the two mating-type alleles of Neurospora Crassa are highly dissimilar. Science 1988; 241(4865): 570-3.

[125] Glass NL, Kaneko I. Fatal attraction: nonself recognition and heterokaryon incompatibility in filamentous fungi. Eukaryot Cell 2003; 2(1): 1-8.

[126] Saupe SJ, Clave C, Begueret J. Vegetative incompatibility in filamentous fungi: Podospora and Neurospora provide some clues. Curr Opin Microbiol 2000; 3(6): 608-12.

[127] Espagne E, Lespinet O, Malagnac F, et al. The genome sequence of the model ascomycete fungus Podospora Anserina. Genome Biol 2008; 9(5): R77.

[128] Shiu PKT, Glass NL. Cell and nuclear recognition mechanisms mediated by mating type in filamentous ascomycetes. Curr Opin Microbiol 2000; 3(2): 183-8.

[129] Shiu PKT, Glass NL. Molecular characterization of Tol, a mediator of mating-type-associated vegetative incompatibility in Neurospora Crassa. Genetics 1999; 151: 545-555.

[130] Lord KM, Read ND. Perithecium morphogenesis in Sordaria Macrospora. Fungal Genet Biol 2011; 48(4): 388-99.

[131] Mayrhofer S, Weber JM, Pöggeler S. Pheromones and pheromone receptors are required for proper sexual development in the homothallic ascomycete Sordaria Macrospora. Genetics 2006; 172(3): 1521-33.

[132] Pöggeler S, Kück U. Comparative analysis of the mating-type loci from Neurospora Crassa and Sordaria Macrospora: identification of novel transcribed orfs. Mol Gen Genet 2000; 263(2): 292-301.

[133] Klix V, Nowrousian M, Ringelberg C, et al. Functional characterization of mat1-1-specific mating-type genes in the homothallic ascomycete Sordaria Macrospora provides new insights into essential and nonessential sexual regulators. Eukaryot Cell 2010; 9(6): 894-905.

[134] Coppin E, Debuchy R, Arnaise S, Picard M. Mating types and sexual development in filamentous ascomycetes. Microbiol Mol Biol Rev 1997; 61(4): 411-28.

[135] Pöggeler S, Risch S, Kück U, Osiewacz HD. Mating-type genes from the homothallic fungus Sordaria Macrospora Are functionally expressed in a heterothallic ascomycete. Genetics 1997; 147(2): 567-80.

[136] Glass NL, Grotelueschen J, Metzenberg RL. Neurospora Crassa a mating-type region. Proc Natl Acad Sci 1990; 87(13): 4912-6.
[137] Nowrousian M, Stajich JE, Chu M, et al. De novo assembly of a 40 $\mathrm{mb}$ eukaryotic genome from short sequence reads: Sordaria Macrospora, a model organism for fungal morphogenesis. PLoS Genet 2010; 6(4): e1000891.

[138] Kamerewerd J, Jansson M, Nowrousian M, Pöggeler S, Kück U. Three alpha-subunits of heterotrimeric $\mathrm{g}$ proteins and an adenylyl cyclase have distinct roles in fruiting body development in the homothallic fungus Sordaria Macrospora. Genetics 2008; 180(1): 191-206.

[139] Zickler D. Observing meiosis in filamentous fungi: Sordaria and Neurospora. In: Kenney S, Ed. Meiosis - cytological methods. Humana Press: Heidelberg. 2009; 91-114.

[140] Bloemendal S, Lord KM, Rech C, et al. A mutant defective in sexual development produces aseptate ascogonia. Eukaryot Cell, 2010; 9(12): 1856-66.

[141] Esser K, Straub J. [Fertility in the heterokaryon from two sterile mutants of sordaria macrospora auersw.]. Zeitschrift für induktive abstammungs- und vererbungslehre, 1956; 87(4): 625-6.

[142] Rech C, Engh I, Kuck U. Detection of hyphal fusion in filamentous fungi using differently fluorescence-labeled histones. Curr Genet 2007; 52: 259-66.

[143] Debuchy R, Turgeon BG. Mating-type structure, evolution, and function in euascomycetes. In: Kües U, Fischer R, Eds. The mycota. I - growth, differentiation, and sexuality. Springer Verlag: Berlin. 2006; 293-323.

[144] Paoletti M, Seymour FA, Alcocer MJ, et al. Mating type and the genetic basis of self-fertility in the model fungus Aspergillus Nidulans. Curr Biol 2007; 17(16): 1384-9.

[145] Murtagh GJ, Dyer PS, Crittenden PD. Sex and the single lichen. Nature 2000; 404(6778): 564.

[146] Engh I, Nowrousian M, Kuck U. Sordaria Macrospora, a model organism to study fungal cellular development. Eur J Cell Biol 2010; 89(12): 864-72.

[147] Seidl V, Seibel C, Kubicek CP, Schmoll M. Sexual development in the industrial workhorse Trichoderma Reesei. Proc Natl Acad Sci 2009; 106(33): 13909-14.

[148] Seibel C, Tisch D, Kubicek CP, Schmoll M. The role of pheromone receptors for communication and mating in Hypocrea Jecorina (Trichoderma Reesei). Fungal Genet Biol 2012; 49(10): 814-24.

[149] Schmoll M, Seibel C, Tisch D, Dorrer M, Kubicek CP. A Novel class of peptide pheromone precursors in ascomycetous fungi. Mol Microbiol 2010; 77(6): 1483-501.

[150] Jones SK, Jr., Bennett RJ. Fungal mating pheromones: choreographing the dating game. Fungal Genet Biol 2011; 48(7): 668-76.

[151] Seibel C, Tisch D, Kubicek CP, Schmoll M. Envoy is a major determinant in regulation of sexual development in Hypocrea Jecorina (Trichoderma Reesei). Eukaryot Cell 2012; 11(7): 885-95.

[152] Billiard S, Lopez-Villavicencio M, Hood ME, Giraud T. Sex, outcrossing and mating types: unsolved questions in fungi and beyond. J Evol Biol 2012; 25(6): 1020-38.

[153] Shear CL, Dodge BO. Life Histories and heterothallism of the red bread-mold fungi of the Monilia Sitophila group. J Agric Res 1927; 34: 1019-42.

[154] Raju NB. Functional heterothallism resulting from homokaryotic conidia and ascospores in Neurospora Tetrasperma. Mycol Res 1992; 96(2): 103-16.

[155] Raju NB, Perkins DD. Diverse programs of ascus development in pseudohomothallic species of Neurospora, Gelasinospora, and Podospora. Dev Genet 1994; 15: 104-18.

[156] Dodge BO. The mechanistics of sexual reproduction in Neurospora. Mycologia 1935; 27(4): 418-38.

[157] Coppin E, Berteaux-Lecellier V, Bidard F, et al. Systematic deletion of homeobox genes in Podospora Anserina uncovers their roles in shaping the fruiting body. PLoS One 2012; 7(5): e37488.

[158] Bistis GN. Trichogynes and fertilization in uni- and bimating type colonies of Neurospora Tetrasperma. Fungal Genet Biol 1996; 20(1): 93-8.

[159] Zickler D, Arnaise S, Coppin E, Debuchy R, Picard M. Altered mating-type identity in the fungus Podospora Anserina leads to selfish nuclei, uniparental progeny, and haploid meiosis. Genetics 1995; 140(2): 493-503.

[160] Berteaux-Lecellier V, Zickler D, Debuchy R, et al. A homologue of the yeast she4 gene is essential for the transition between the syncytial and cellular stages during sexual reproduction of the fungus Podospora Anserina. Embo j 1998; 17(5): 1248-58. 
[161] Arnaise S, Zickler D, Le Bilcot S, Poisier C, Debuchy R. Mutations in mating-type genes of the heterothallic fungus Podospora Anserina lead to self-fertility. Genetics 2001; 159(2): 545-56.

[162] Esser K. Podospora Anserina. In: King RC, Ed. Handbook of Genetics. Plenum Press: New York. 1974; 531-51.

[163] Corcoran P, Jacobson DJ, Bidartondo MI, et al. Quantifying functional heterothallism in the pseudohomothallic ascomycete Neurospora Tetrasperma. Fungal Biol 2012; 116(9): 962-75.

[164] Menkis A, Jacobson DJ, Gustafsson T, Johannesson H. the matingtype chromosome in the filamentous ascomycete Neurospora Tetrasperma represents a model for early evolution of sex chromosomes. PLoS Genet 2008; 4(3): e1000030.

[165] Jacobson DJ, Raju NB, Freitag M. Evidence for the absence of meiotic silencing by unpaired DNA in Neurospora Tetrasperma. Fungal Genet Biol 2008; 45(3): 351-62.

[166] Ellison CE, Stajich JE, Jacobson DJ, et al. Massive changes in genome architecture accompany the transition to self-fertility in the filamentous fungus Neurospora Tetrasperma. Genetics 2011; 189(1): 55-69.

[167] Gallegos A, Jacobson DJ, Raju NB, Skupski MP, Natvig DO. Suppressed recombination and a pairing anomaly on the matingtype chromosome of Neurospora Tetrasperma. Genetics 2000; 154(2): 623-33.

[168] Merino ST, Nelson MA, Jacobson DJ, Natvig DO. Pseudohomothallism and evolution of the mating-type chromosome in Neurospora Tetrasperma. Genetics 1996; 143(2): 789-99.

[169] Pontecorvo G, Roper JA, Hemmons LM, Macdonald KD, Bufton AW. The genetics of Aspergillus Nidulans. Adv Genet 1953; 5: 141-238.

[170] Beraha L, Garber ED. Relative heterothallism and production of hybrid perithecia by auxotrophic mutants of Glomerella Cingulata from apple. J Phytopathol 1985; 112(1): 32-9.

[171] Debuchy R, Berteaux-Lecellier V, Silar P. Mating systems and sexual morphogenesis in acomycetes. In: Borkovich KA, Ebbole DJ, Eds. Cellular and molecular biology of filamentous fungi. American Society for Microbiology Press: Wahington, DC. 2010; 501-35.

[172] Butcher AC. The relationship between sexual outcrossing and heterokaryon incompatibility in Aspergillus Nidulans. Heredity (Edinb) 1968; 23(3): 443-52.

[173] Bruggeman J, Debets AJ, Hoekstra RF. Selection arena in Aspergillus Nidulans. Fungal Genet Biol 2004; 41(2): 181-8.

[174] Hoffmann B, Eckert SE, Krappmann S, Braus GH. Sexual diploids of Aspergillus Nidulans do not form by random fusion of nuclei in the heterokaryon. Genetics 2001; 157(1): 141-7.

[175] Galagan JE, Calvo SE, Cuomo C, et al. Sequencing of aspergillus nidulans and comparative analysis with A. Fumigatus and $A$. Oryzae. Nature 2005; 438(7071): 1105-15.

[176] Dyer PS, Paoletti M, Archer DB. Genomics reveals sexual secrets of Aspergillus. Microbiology 2003; 149(Pt 9): 2301-3.

[177] Sohn KT, Yoon KS. Ultrastructural study on the cleistothecium development in Aspergillus Nidulans. Mycobiology 2002; 30(3): 117-27.

[178] Lopez-Villavicencio M, Debets AJ, Slakhorst M, Giraud T, Schoustra SE. Deleterious effects of recombination and possible nonrecombinatorial advantages of sex in a fungal model. J Evol Biol 2013; 26(9): 1968-78.

[179] Swart K, Debetes AJM. Genetics of Aspergillus. In: Kück U, Ed. The Mycota: Genetics and Biotechnology II. Springer Verlag: Berlin Heidelberg. 2004; 21-34.

[180] Dyer PS, O'Gorman CM. Sexual development and cryptic sexuality in fungi: insights from Aspergillus species. FEMS Microbiol Rev 2012; 36(1): 165-92.

[181] O'Gorman CM, Fuller H, Dyer PS. Discovery of a sexual cycle in the opportunistic fungal pathogen Aspergillus Fumigatus. Nature 2009; 457(7228): 471-4.

[182] Horn BW, Ramirez-Prado JH, Carbone I. The sexual state of Aspergillus Parasiticus. Mycologia 2009; 101(2): 275-80.

[183] Horn BW, Moore GG, Carbone I. Sexual reproduction in Aspergillus Flavus. Mycologia 2009; 101(3): 423-9.

[184] Horn BW, Moore GG, Carbone I. Sexual reproduction in aflatoxinproducing Aspergillus Nomius. Mycologia 2011; 103(1): 174-83.

[185] Whittle CA, Nygren K, Johannesson H. Consequences of reproductive mode on genome evolution in fungi. Fungal Genet Biol 2011; 48(7): 661-7.
[186] Veses V, Richards A, Gow NAR. Vacuoles and fungal biology. Curr Opin Microbiol 2008; 11(6): 503-10.

[187] Smith ML, Bruhn JN, Anderson JB. The fungus Armillaria Bulbosa is amongst the largest and oldest living organisms. Nature 1992; 356: 428-31.

[188] Boddy L. Interspecific combative interactions between wooddecaying basidiomycetes. FEMS Microbiol Ecol 2000; 31(3): 18594.

[189] Wang Y, Wu J, Park ZY, et al. Comparative secretome investigation of magnaporthe oryzae proteins responsive to nitrogen starvation. J Proteome Res 2011; 10(7): 3136-48.

[190] Boer W, Folman LB, Summerbell RC, Boddy L. Living in a fungal world: impact of fungi on soil bacterial niche development. FEMS Microbiol Rev 2005; 29(4): 795-811.

[191] de Boer W, Folman LB, Gunnewiek PJ, et al. Mechanism of antibacterial activity of the white-rot fungus Hypholoma Fasciculare colonizing wood. Can J Microbiol 2010; 56(5): 380-8.

[192] A'Bear AD, Boddy L, Jones TH. Bottom-up determination of soil collembola diversity and population dynamics in response to interactive climatic factors. Oecologia 2013; 173(3): 1083-7.

[193] Heilmann-Clausen J, Boddy L. Inhibition and stimulation effects in communities of wood decay fungi: exudates from colonized wood influence growth by other species. Microb Ecol 2005; 49(3): 399406.

[194] Rayner ADM, Griffith GS, Wildman HG. Induction of metabolic and morphogenic changes during mycelial interactions among species of higher fungi. Biochem Soc T 1994; 22: 389-94.

[195] Humphris SN, Bruce A, Buultjens E, Wheatley RE. The effects of volatile microbial secondary metabolites on protein synthesis in Serpula Lacrymans. FEMS Microbiol Lett 2002; 210(2): 215-9.

[196] Wheatley RE. The consequences of volatile organic compound mediated bacterial and fungal interactions. Anton Leeuw 2002; 81(1-4): 357-64.

[197] Morath SU, Hung R, Bennett JW. Fungal volatile organic compounds: a review with emphasis on their biotechnological potential. Fungal Biol Rev 2012; 26(2-3): 73-83.

[198] Wenke K, Kai M, Piechulla B. Belowground volatiles facilitate interactions between plant roots and soil organisms. Planta 2010 231(3): 499-506.

[199] Campos VP, de Pinho RSC, Souza Freire E. Volatiles produced by interacting microorganisms potentially useful for the control of plant pathogens. Cien Agrotec 2010; 34(3): 525-35.

[200] Dicke M, Sabelis MW. Infochemical terminology: based on costbenefit analysis rather than origin of compounds? Funct Ecol 1988; 2: 131-9.

[201] Nordlund DA, Lewis WJ. Terminology of chemicals releasing stimuli in intraspecific and interspecific interactions. J Chem Ecol 1976; 2(2): 211-20.

[202] Schubert M, Fink S, Schwarze FWMR. In Vitro screening of an antagonistic trichoderma strain against wood decaying fungi. Arboric J 2008; 31: 227-48.

[203] Chamoun R, Aliferis KA, Jabaji SH. Characterization and transcriptional regulation of Stachybotrys Elegans mitogenactivated-protein kinase gene smka following mycoparasitism and starvation conditions. Curr Genet 2013; 59(1-2): 43-54.

[204] Delgado-Jarana J, Sousa S, Gonzalez F, Rey M, Llobell A. Thhog1 controls the hyperosmotic stress response in Trichoderma Harzianum. Microbiology 2006; 152(6): 1687-700.

[205] Divon HH, Fluhr R. Nutrition acquisition strategies during fungal infection of plants. FEMS Microbiol Lett 2007; 266(1): 65-74.

[206] Bidartondo MI, Read DJ, Trappe JM, et al. The dawn of symbiosis between plants and fungi. Biol Lett 2011; 7(4): 574-7.

[207] Harrison MJ. Signaling in the arbuscular mycorrhizal symbiosis. Annu Rev Microbiol 2005; 59: 19-42.

[208] Bonfante P, Genre A. Mechanisms underlying beneficial plantfungus interactions in mycorrhizal symbiosis. Nat Commun 2010; $1: 48$.

[209] Harrison MJ. Cellular programs for arbuscular mycorrhizal symbiosis. Curr Opin Plant Biol 2012; 15(6): 691-8.

[210] De Wit PJ, Mehrabi R, Van den Burg HA, Stergiopoulos I. Fungal effector proteins: past, present and future. Mol Plant Pathol 2009; 10(6): 735-47.

[211] Stergiopoulos I, de Wit PJ. Fungal effector proteins. Annu Rev Phytopathol 2009; 47: 233-63. 
[212] Rafiqi M, Jelonek L, Akum NF, Zhang F, Kogel KH. Effector candidates in the secretome of Piriformospora Indica, a Ubiquitous plant-associated fungus. Front Plant Sci 2013; 4: 228.

[213] Dodds PN, Rathjen JP. Plant immunity: towards an integrated view of plant-pathogen interactions. Nat Rev Genet 2010; 11(8): 539-48.

[214] Jaffe MJ, Leopold AC, Staples RC. Thigmo responses in plants and fungi. Am J Bot 2002; 89(3): 375-82.

[215] Hacquard S, Kracher B, Maekawa T, et al. Mosaic genome structure of the barley powdery mildew pathogen and conservation of transcriptional programs in divergent hosts. Proc Natl Acad Sci USA 2013; 110(24): E2219-28.

[216] de Jonge R, Bolton MD, Thomma BP. How filamentous pathogens co-opt plants: the ins and outs of fungal effectors. Curr Opin Plant Biol 2011; 14(4): 400-6.

[217] Saunders DG, Win J, Cano LM, et al. Using hierarchical clustering of secreted protein families to classify and rank candidate effectors of rust fungi. PLoS One, 2012; 7(1): e29847.

[218] Sexton AC, Howlett BJ. Parallels in fungal pathogenesis on plant and animal hosts. Eukaryot Cell, 2006; 5(12): 1941-9.

[219] Torto-Alalibo T, Collmer CW, Gwinn-Giglio M, et al. Unifying themes in microbial associations with animal and plant hosts described using the gene ontology. Microbiol Mol Biol Rev 2010; 74(4): 479-503.

[220] Tudzynski P, Heller J, Siegmund U. Reactive oxygen species generation in fungal development and pathogenesis. Curr Opin Microbiol 2012; 15(6): 653-9.

[221] Montibus M, Pinson-Gadais L, Richard-Forget F, Barreau C, Ponts N. Coupling of transcriptional response to oxidative stress and secondary metabolism regulation in filamentous fungi. Crit Rev Microbiol 2013.

[222] Albuquerque P, Casadevall A. Quorum sensing in fungi-a review. Med Mycol 2012; 50(4): 337-45.

[223] Mallick EM, Bennett RJ. Sensing of the microbial neighborhood by Candida Albicans. PLoS Pathog 2013; 9(10): e1003661.
[224] Aldabbous MeS, Roca MG, Stout A, et al. The ham-5, rcm-1 and rco-1 genes regulate hyphal fusion in Neurospora Crassa. Microbiology 2010; 156(9): 2621-9.

[225] Aramayo R, Peleg Y, Addison R, Metzenberg R. Asm-1+, a Neurospora Crassa gene related to transcriptional regulators of fungal development. Genetics 1996; 144(3): 991-1003.

[226] Araujo-Palomares, Richthammer C, Seiler S, Castro-Longoria E. Functional characterization and cellular dynamics of the cdc-42 rac - cdc-24 module in Neurospora Crassa. PLoS One 2011; 6(11): e27148.

[227] Araujo-Palomares CL, Riquelme M, Castro-Longoria E. The Polarisome component spa-2 localizes at the apex of Neurospora Crassa and Partially colocalizes with the spitzenkörper. Fungal Genet Biol 2009; 46(8): 551-63.

[228] Justa-Schuch D, Heilig Y, Richthammer C, Seiler S. Septum formation is regulated by the rho4-specific exchange factors bud3 and rgf3 and by the landmark protein bud4 in Neurospora Crassa. Mol Microbiol 2010; 76(1): 220-35.

[229] Vogt N, Seiler S. The rho1-specific gtpase-activating protein $\operatorname{lrg} 1$ regulates polar tip growth in parallel to ndr kinase signalling in Neurospora. Mol Biol Cell 2008; 19: 4554-69.

[230] Bowman SM, Piwowar A, Al Dabbous Me, Vierula J, Free SJ. Mutational analysis of the glycosylphosphatidylinositol (gpi) anchor pathway demonstrates that gpi-anchored proteins are required for cell wall biogenesis and normal hyphal growth in Neurospora Crassa. Eukaryot Cell 2006; 5(3): 587-600.

[231] Raju NB. Meiosis and ascospore genesis in Neurospora. Eur J Cell Biol 1980; 23(1): 208-23.

[232] Bistis GN, Perkins DD, Read ND. Different cell types in Neurospora Crassa. Fungal Genet Newsl 2003; 50: 17-9.

[233] Esser K. Cryptogams: Cyanobacteria, Algae, Fungi, Lichens. London: Cambridge University Press; 1982.

[234] Esser K, Graw D. Homokaryotic Fruiting in the BipolarIncompatible Ascomycete Podospora Anserina. Mycologia 1980; 72(3): 534-41.

(C) Lichius and Lord; Licensee Bentham Open.

This is an open access article licensed under the terms of the Creative Commons Attribution Non-Commercial License (http://creativecommons.org/ licenses/by-nc/3.0/), which permits unrestricted, non-commercial use, distribution and reproduction in any medium, provided the work is properly cited. 